\title{
Comparative genomics reveals functional transcriptional control sequences in the Prop1 gene
}

\author{
Robert D. Ward · Shannon W. Davis · MinChul Cho $\cdot$ Constance Esposito · \\ Robert H. Lyons · Jan-Fang Cheng · Edward M. Rubin · Simon J. Rhodes · \\ Lori T. Raetzman · Timothy P. L. Smith $\cdot$ Sally A. Camper
}

Received: 4 December 2006/ Accepted: 26 January 2007/Published online: 8 June 2007

(C) Springer Science+Business Media, LLC 2007

\begin{abstract}
Mutations in PROPI are a common genetic cause of multiple pituitary hormone deficiency (MPHD).
\end{abstract}

R. D. Ward · MinChul Cho · S. A. Camper

Graduate Program in Cellular and Molecular Biology,

University of Michigan, Ann Arbor, Michigan, USA

S. W. Davis - L. T. Raetzman - S. A. Camper

Department of Human Genetics, University of Michigan,

Ann Arbor, Michigan, USA

C. Esposito · R. H. Lyons

DNA Sequencing Core Facility, University of Michigan,

Ann Arbor, Michigan, USA

J.-F. Cheng · E. M. Rubin

DOE Joint Genome Institute, U.S. Department of Energy,

Walnut Creek, California, USA

\section{S. J. Rhodes}

Department of Biology, Indiana University-Purdue University

Indianapolis (IUPUI), Indianapolis, Indiana, USA

T. P. L. Smith

U.S. Meat Animal Research Center, U.S. Department of Agriculture, Agricultural Research Service (USDA/ARS),

Clay Center, Nebraska, USA

S. A. Camper $(\square)$

4909 Buhl Bldg., 1241 E. Catherine St., Ann Arbor

MI 48109-0618, USA

e-mail: scamper@umich.edu

Present Address:

L. T. Raetzman

Department Molecular and Integrative Physiology,

University of Illinois, Urbana, Illinois, USA

Present Address:

R. D. Ward

Department of Molecular and Cellular Biology,

Baylor College of Medicine, Houston, Texas, USA
We used a comparative genomics approach to predict the transcriptional regulatory domains of Propl and tested them in cell culture and mice. A BAC transgene containing Propl completely rescues the Propl mutant phenotype, demonstrating that the regulatory elements necessary for proper $P R O P 1$ transcription are contained within the BAC. We generated DNA sequences from the PROPI genes in lemur, pig, and five different primate species. Comparison of these with available human and mouse PROPl sequences identified three putative regulatory sequences that are highly conserved. These are located in the PROPI promoter proximal region, within the first intron of $P R O P 1$, and downstream of $P R O P 1$. Each of the conserved elements elicited orientation-specific enhancer activity in the context of the Drosophila alcohol dehydrogenase minimal promoter in both heterologous and pituitary-derived cells lines. The intronic element is sufficient to confer dorsal expansion of the pituitary expression domain of a transgene, suggesting that this element is important for the normal spatial expression of endogenous Propl during pituitary development. This study illustrates the usefulness of a comparative genomics approach in the identification of regulatory elements that may be the site of mutations responsible for some cases of MPHD.

\section{Introduction}

All vertebrates have pituitary glands composed of specialized hormone-producing cells (Matsumoto and Ishii 1987). The individual hormones are evolutionarily conserved, although their function varies across the classes of Animalia. This conservation suggests that genetic regulation of pituitary function may be conserved. 
In humans, growth insufficiency resulting from pituitary hormone deficiency is not infrequent, occurring in approximately 1 in 4000 live births (Procter et al. 1998; Vimpani et al. 1977). Growth hormone (GH) insufficiency is the most common type of dwarfism and usually results from mutations in the GH gene cluster (Braga et al. 1986; Mullis et al. 1990). Multiple pituitary hormone deficiencies (MPHD) result from mutations in transcription factors important for the normal development and function of the pituitary gland, including POUIFI (PIT1), Prophet of PIT1 (PROP1), HESX1, LHX3, LHX4, and SOX3 (Bhangoo et al. 2006; Cogan et al. 1998; Laumonnier et al. 2002; Machinis et al. 2001; Mendonca et al. 1999; Netchine et al. 2000; Pfäffle et al. 1992; Radovick et al. 1992; Tajima et al. 2003; Wu et al. 1998). The first transcription factor to be linked to MPHD was PIT1 (Tatsumi et al. 1992). Patients with mutations in PIT1 generally have deficiencies in GH, prolactin (PRL), and thyroid-stimulating hormone (TSH) as well as profound pituitary hypoplasia (Cohen et al. 1996). Mutations in PROPI are a common genetic cause of familial MPHD. Patients with PROPI mutations exhibit progressive hormone loss with varying age of onset and severity (Bottner et al. 2004; Fluck et al. 1998). Most common are deficiencies in PRL, GH, and TSH as well as follicle-stimulating hormone (FSH) and luteinizing hormone (LH) (Agarwal et al. 2000; Deladoey et al. 1999). Progressive adrenocorticotrophic hormone (ACTH) loss presents as late as the third decade of life (Bottner et al. 2004). Some MPHD cases, however, cannot be traced to mutations in the protein-coding or intron-exon splice sites in the DNA sequence of known genes important for pituitary development.

The mechanism of PROPI action has been studied extensively in two mouse models, the Ames dwarf (Prop $^{\mathrm{df}}{ }^{\text {) }}$ and the Prop ${ }^{\text {null }}$ (Nasonkin et al. 2004; Ward et al. 2005). In mice, Propl is expressed throughout the developing Rathke's pouch in a dorsal to ventral expression gradient from about embryonic day 10 (e10) until about e16 (Sornson et al. 1996). PROP1 transcripts are present in the adult pituitaries of human and pig, although the levels were not quantified relative to the embryonic pituitary (Nakamura et al. 1999a, 1999b; Skelly et al. 2000; Sloop et al. 2000; Usui et al. 2000). A number of Prop1 downstream targets have been identified, including Pitl, Hesx1, Tle3, and Notch2 (Brinkmeier et al. 2003; Gage et al. 1996a; Raetzman et al. 2004).

It is of great interest to identify the transcriptional regulators of Propl because it is pituitary-specific, unlike many of the other key regulators of pituitary development: Pitx1, Pitx2, Lhx3,Lhx4, and Hesx1. Each of these genes is expressed prior to Propl and is a candidate for transcriptional regulation of Prop1. Propl expression is activated in Pitxl and Pitx2 single mutants, but this may be due to the ability of Pitxl and Pitx2 to compensate for each other (Suh et al. 2002; Szeto et al. 1999). Propl expression also appears to be initiated normally in Hesxl- and Lhx4-deficient mice (Dasen et al. 2001; Raetzman et al. 2002). Thus, the spatial and temporal regulation of Propl expression is not fully explained by these genes, suggesting that additional factors may be involved.

The regulation of gene expression involves the cooperation of a variety of transcription factors in a tissue-, temporal-, and/or spatial-specific fashion that interact with cis-acting regulatory elements in DNA sequences (Kleinjan and van Heyningen 2005). The identification of these elements can be difficult because they may be located at a considerable distance from the gene or even within the introns of neighboring genes (Bagheri-Fam et al. 2001; Lang et al. 2003; Lettice et al. 2003). The identification of these elements is facilitated by comparative genomics in the form of cross-species DNA comparisons. The alignment of the DNA sequences of orthologous genes from different species, both closely and distantly related, can reveal potential conserved regulatory elements that can then be analyzed in vivo (Boffelli et al. 2004; Nobrega and Pennacchio 2004; Pennacchio and Rubin 2001). Transcription factors involved in development, like Propl, are often conserved among vertebrates, and their regulatory sequences are also likely to be conserved (Plessy et al. 2005).

In this study we report the sequence of the PROPI gene from several mammals and utilize cross-species PROP1 protein sequence comparison to verify the conservation of the functional domains of the protein and use genomic sequence comparison to identify putative transcriptional regulatory elements in the noncoding regions of the Propl gene. This analysis revealed the presence of three conserved noncoding elements within and near the gene. Each of them exhibited orientation-dependent enhancer activity in tissue culture, and an element in intron 1 conferred tissue-specific and unique spatial expression in transgenic mice. These studies establish a functional role for the intronic element in Propl gene regulation. Finally, using bacterial artificial chromosome (BAC) transgene rescue of the Propl mutant phenotype, we demonstrate that all of the sequences necessary for functional expression of Propl are located within the BAC.

\section{Materials and methods}

Protein and DNA sequence

A BAC clone of approximately $200 \mathrm{~kb}$ and containing the pig (Sus scrofa) Propl gene was identified, and DNA was isolated from it. A shotgun sequencing library was pre- 
pared from that BAC by using SeqWright (Houston, TX), and the resulting subclones were sequenced at the University of Michigan Sequencing Core using Applied Biosystems (Foster City, CA) sequencers (Model 3700) and BigDye V1.1 terminator chemistry, according to standard manufacturer's protocols. Sequence assembly of the shotgun sequence data was performed using phred and phrap (Ewing and Green 1998), and consed (Gordon et al. 1998), resulting in $6 \mathrm{X}$ draft sequence coverage. Limited finishing was performed based on the "autofinish" option in consed to close some gaps, especially those in the vicinity of the Propl gene. A total of ten draft contigs of $1 \mathrm{~kb}$ or greater were obtained in the final assembly, accounting for $196 \mathrm{~kb}$, or an estimated $98 \%$ of the original BAC. The sequences have a phred Q-score of 20 or higher, with the majority being Q40 or better. The BAC sequences were submitted to GenBank (NCBI; http://www.ncbi.nlm.nih.gov; accession number EF590118). One contig of approximately $26.3 \mathrm{~kb}$ contained the Sus scrofa Propl gene, including $13.8 \mathrm{~kb}$ of $5^{\prime}$ flanking sequence, $3.7 \mathrm{~kb}$ encoding the Propl gene, and $8.7 \mathrm{~kb}$ of $3^{\prime}$ flanking sequence. A set of lemur BACs containing the Propl gene were isolated from a library derived from a cell line of the ring-tailed lemur (Lemur catta; AG07100C, Coriell Cell Repositories, Camden, NJ) using a human PROPI exon 3 probe. One lemur BAC, LBNL-2 102B17, was sequenced from ends of $3 \mathrm{~kb}$ subclones to approximately tenfold coverage using BigDye terminators (Applied Biosystems) and assembled into ordered and oriented contigs with the Phred-Phrap-Consed suite (Ewing and Green 1998; Gordon et al. 1998). The assembled BAC sequence was submitted to GenBank with accession number AC162436. Propl gene sequence from gorilla (Gorilla gorilla), Black and Red Howler (Alouatta belzebul), Brown Capuchin (Cebus apella), and Gelada Baboon (Theropithecus gelada) was amplified from genomic DNA (gift from Dr Deborah Gumucio, University of Michigan, Ann Arbor, MI) by using the forward primer (5'CCTGCTCCCAGGAGGGGATT- $3^{\prime}$ ) that corresponded to the human PROP1 $5^{\prime}$ flanking sequence that was highly conserved between mouse and human, and as the reverse primer (5'-AGGCTGGGGATCACCTTGGTG-3') that corresponded to the $3^{\prime}$ UTR of the human PROPI gene. cDNA sequence was determined by using the high conservation between primate exon splice acceptor/donor sites to assemble the cDNA sequence from the gene sequence. The protein sequence was then translated from the cDNA as described above. The Propl gene sequences were deposited in GenBank with accession numbers DQ177426 for gorilla, DQ177425 for capuchin monkey, DQ177427 for howler monkey, and DQ177424 for baboon.

The 20-kb human PROPI was obtained from the human chromosome 5 contig sequences from GenBank accession numbers NT086684 and NT023133. The 20-kb mouse
(Mus musculus) Propl sequence was obtained from the mouse chromosome 11 contig sequences from GenBank accession number NT096135. The Propl genomic sequence for the chimpanzee (Pan troglodytes) was obtained via the Berkley Genome Pipeline from the genome VISTA analysis program [http://www.genome.lbl.gov/vista/index.shtml (Couronne et al. 2003)]. The cDNA and protein sequences were determined as described above. The Propl genomic sequence for the rat and partial genomic sequence for the fugu (Fugu rubripes) and zebrafish (Danio rerio) were obtained by searching the UCSC genome browser [http://www.genome.ucsc.edu (Kent 2002)] for the closest matches to PROP1. The partial protein sequences for the fugu and zebrafish were determined by the translation of the partial gene sequence in all three frames to identify the PROP1 homedomain and transactivation domain sequence. The rat (Rattus norvegicus) cDNA sequence was obtained from GenBank (accession number NM153627) and translated as described above. Propl genomic sequence was obtained for the dog (Canis familiaris; AF126157) and sheep (Ovis aries; AY533708) and PROP1 protein sequence for human (NP006252), pig (NP001001263), cow (Bos taurus; NP777103), sheep (NP001009767), mouse (P97458), dog (NP001018643), and partial protein sequence for the chicken (Gallus gallus; AB037110) was obtained from the NCBI website.

\section{Sequence analysis}

ClustalW alignment for protein and DNA sequences were done with the LASERGENE Navigator Meg align sequence alignment program (DNASTAR Inc., Madison, WI). Mouse, rat, human, and chimp chromosome comparisons were done using the University of California, Santa Cruz (UCSC) genome browser [http://www.genome.ucsc.edu (Kent et al. 2002)]. The pig Propl BAC contigs were compared to the mouse genome using the genome VISTA program [http://www.genome.lbl.gov/vista/index.shtml (Couronne et al. 2003)]. The 20-kb PROP1 genomic sequences for the human, lemur, pig, and mouse were analyzed with the mVISTA [http://www.genome.lbl.gov/vista/index.shtml (Bray et al. 2003)] comparative genomics program to determine the identity of the conserved noncoding elements.

\section{Plasmid construction}

The $C E-A / L a c Z$ plasmid was constructed for the targeted knockout of the Propl gene (Nasonkin et al. 2004). The $C E-B+C E-A / L a c Z$ plasmid was constructed by digesting the $C E-A / L a c Z$ plasmid with $X h o I$ and subcloning the region containing $3 \mathrm{~kb}$ of the Propl 5' flanking region, the LacZ coding region, and mouse protamine 1 splice and 
polyadenylation regions into the XhoI site of pBluescript SK+ (Stratagene, La Jolla, CA). A 9.5-kb Propl genomic clone (Nasonkin et al. 2004), which was generated from a P1 clone containing the entire Propl gene, was used as a template to amplify the $C E-B$ region with a series of primers that engineered flanking loxP sites ( $5^{\prime}$-ATAAC TTCGTATAGCATACATTATACGAAGTTAT- $\left.3^{\prime}\right)$. The floxed $C E-B$ fragment was subcloned into pGEM-T Easy (Promega, Madison, WI). This $C E-B$ lox $P$ construct was digested with $N o t \mathrm{I} / X b a \mathrm{I}$ and ligated into the NotI/XbaI sites of the pBluescript $\mathrm{SK}+$ vector that contained the $3-\mathrm{kb}$ Propl 5' flanking sequence with the $L a c Z p A$ reporter.

The $\alpha$ Gsu-Prop $1 \triangle C E-B$ plasmid was made by creating a chimera of the Propl intron 1 in which the $C E-B$ region was deleted. First, the intron sequence for the $5^{\prime}$ flank of $C E-B$ was amplified from the 9.5-kb Propl genomic clone (Nasonkin et al. 2004) by using primers (5'-GGTTTGGGTG GCTAGCCATGGAA- $3^{\prime}$ and $5^{\prime}$-TTCCCAAGCACCTCC TTCATATCCCACCCCCCAACTAAGCACCC-3') that allowed this fragment to be annealed to the $C E-B 3^{\prime}$ flanking sequence that was also amplified from the 9.5-kb Propl plasmid with the primers 5'-CCTCCTATAAGCCTCAGA GCT-3' and 5'-GGGTGCTTAGTTGGGGGGTGGGATAT GAAGGAGGTGCTTGG G-3'. These two PCR products were engineered with overlapping tails that could be annealed together to create a chimeric Propl intron1 with the $C E-B$ region deleted. This chimera was amplified with the primers $5^{\prime}$-GGTTTGGGTGGCTAGCCATGGAA-3' and 5'-CCTCCTATAAGCCTCAGAGCT-3', digested with $N c o I$ and $S a c I$, and subcloned into the $\alpha$ Gsu-Propl plasmid (Cushman et al. 2001) to create the desired transgenic construct. This $\alpha$ Gsu-Prop $1 \Delta C E-B$ was subcloned into pBluescript $\mathrm{SK}+$ by an $E c o \mathrm{R} 1$ partial digest. The $C E-B+\alpha G s u$ Prop $1 \triangle C E-B$ plasmid was made by amplifying the $C E-B$ lox $P$ region from the $C E-B+C E-A / L a c Z$ plasmid with the primers 5'-GGTATCGATTACCCTAGAGGGCAGTGCA GTGCCTG- $3^{\prime}$ and $5^{\prime}$-GGAATCGATATCTCTTTGCTGT CTATCAATGACGT- $3^{\prime}$ that engineered $\mathrm{ClaI}$ sites at the ends of the PCR product to allow the subcloning of this $C E-B$ loxP region into the ClaI site of $\alpha G s u-P r o p 1 \triangle C E-B$.

The 584-bp $C E-A$ region was amplified from the $9.5-\mathrm{kb}$ Propl genomic clone with primers to engineer HindIII sites at the ends the sequence (5'-GTCTGGAAGCTTGC TGGTGAGGCTG-3' and 5'-GGAAGCTTGTCTTGGAG AAGAGACCTCCTCCTGG-3') and subcloned in both the forward and reverse orientations into the HindIII site of the pDeltaODLO 02 plasmid (Iniguez-Lluhi et al. 1997) obtained from Dr. Jorge Iniguez-Lluhi (University of Michigan, Ann Arbor, MI) that contained the Drosophila alcohol dehydrogenase $(A D H)$ minimal promoter and the firefly luciferase reporter gene. The 508-bp $C E-B$ region was PCR amplified from the 9.5-kb Propl plasmid with primers that engineered EcoRI sites at the ends (5'-CGGAAGAATT
CTGGTTGCCCAAGGTCC- ${ }^{\prime}$ ' and $5^{\prime}$-GCCACTCGCAGA ATTCATTTC- $3^{\prime}$ ) and subcloned into pBluescript (Stratagene) at the $E c o$ RI site. The $C E-B$ was then digested with $S m a \mathrm{I} / K p n \mathrm{I}$ and subcloned onto a version of pGL3basic (Promega) that contained the $T K$ minimal promoter inserted into the $B g l \mathrm{I} / H$ HindIII sites. The $C E-B$ region was released from this plasmid by digestion with $X h o I$ and subcloned into the XhoI site of pDeltaODLO 02 in both the reverse and forward orientations. The 1196-bp $C E-C$ region was amplified from the 9.5-kb plasmid (5'-GGA GTACTGGGACCCTTAAGGCCCTTGGGCTGCAGG-3' and 5'-GGAGTACTGGAGTCTGAGACAGGAAGACTG AGAG-3'), cloned in to the pGEM-T Easy vector (Promega), digested with NotI, and subcloned into the NotI site of pDeltaODLO 02 in the forward and reverse orientations.

\section{Cell culture}

Monkey fibroblast CV-1 cells (American Type Culture Collection, Manassas, VA), mouse pituitary gonadotrope $\alpha$ T3-1 cells (Dr. Pamela Mellon, University of San Diego, La Jolla, CA), rat anterior pituitary GH3 cells, and mouse pituitary corticotrope AtT-20 cells were maintained at $37^{\circ} \mathrm{C} / 5 \% \mathrm{CO}_{2}$ in Dulbecco's Modified Eagle Medium (Invitrogen, Carlsbad, CA) supplemented with $10 \%$ heat inactivated fetal bovine serum (Hyclone, Logan, UT) and 100 units/ml penicillin-streptomycin (Invitrogen). The GH3 and AtT-20 cell lines were obtained from Dr. Audrey Seasholtz (University of Michigan, Ann Arbor, MI).

Transient transfection and Dual-Luciferase ${ }^{\circledR}$ Reporter Assay

Cells were plated onto 24-well plastic plates (Fisher Scientific, Fair Lawn, NJ) at a density of $0.4 \times 10^{5}$ cells/well for CV-1, $0.7 \times 10^{5}$ cells/well for $\alpha \mathrm{T} 3-1,1.0 \times 10^{5}$ cells/ well for GH3, and $1.2 \times 10^{5}$ cells/well for AtT-20 cells, such that cells were $40 \%-60 \%$ confluent the next day. DNA cocktails totaling $0.3 \mu \mathrm{g} /$ well $[0.08 \mu \mathrm{g}$ enhancer construct, $0.218 \mu \mathrm{g}$ pBluescript $\mathrm{SK}+, 0.002 \mu \mathrm{g}$ (cytomegalovirus) $C M V$-Renilla luciferase (Promega) internal control in $400 \mu \mathrm{l}$ serum-free DMEM] were transfected into cultured cells using Fugene 6 (Roche, Indianapolis, IN) at a 12:5 ratio according to the manufacturer's protocol. The pDeltaODLO 02 plasmid that contains the $A D H$ minimal promoter with the firefly luciferase reporter gene was used as a negative control and determined as basal level. Fortyeight hours after transfection, Dual-Luciferase Reporter Assay (Promega) was performed according to the manufacturer's protocol and measured using the Lmax Micro plate Illuminometer (Molecular Devices, Sunnyvale, CA) with the SOFTmax Pro software (Molecular Devices). The 
results were normalized to the $C M V$-Renilla luciferase internal control. All assays were done in triplicate and the results were repeated a total of three times. Results were averaged and expressed as percent activity over basal.

Maintenance, generation, and genotyping of transgenic mice

To generate the BAC transgenic mice, BAC RP23-250I22 (supplied by Pieter J. de Jong, Childrens Hospital Oakland Research Institute) was purified over a Nucleobond AX column (BD (Biosciences) and injected into pronuclei of fertilized eggs generated from a cross between DF/BPropl $^{\mathrm{df} / \mathrm{+}}$ males of mixed genetic background (Buckwalter et al. 1991) and $(\mathrm{SJL} / \mathrm{J} \times \mathrm{C} 57 \mathrm{BL} / 6 \mathrm{~J}) \quad \mathrm{F}_{1}$ females. BAC transgenic; Propl $^{\mathrm{df} /+}$ mice were crossed to N6-B6-Propl ${ }^{+-}$ mice (Nasonkin et al. 2004) to generate BAC transgenic;

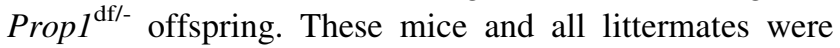
weighed, photographed, and genotyped at weaning.

The presence of the BAC was assessed by PCR using primers designed to amplify products that span the junction between the BAC backbone and the mouse genomic DNA (Sp6 end 5'-CATATTTTCCCCATCCACCACCAT- $3^{\prime}$ and 5'-TTCCCGCAAGAGCAAACACAAC-3'; T7 end 5'-CC GGAAGGAGCTGACTGGGTTGA- $3^{\prime}$ and $5^{\prime}$-TGGGCAT TGAGCTTTCTGGGTTTT-3'). Previously described primers were used to genotype the Prop $I^{\text {df }}$ allele (Cushman et al. 2001) and Propl null allele (Nasonkin et al. 2004).

The $\alpha G S U$ Propl transgenic mouse lines $\operatorname{TgN}(C g a-$

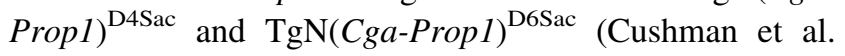
2001; Vesper et al. 2006) have been maintained in the mouse facility at the University of Michigan. Newborns were obtained by mating transgenic males of the D4 or D6 $\alpha$ Gsu-Prop1 transgenic lines with C57BL/6J females (The Jackson Laboratory, Bar Harbor, ME). Genomic DNA was prepared from tail biopsies of all progeny born and then screened for the $\alpha$ Gsu-Propl transgene as previously described (Cushman et al. 2001).

To create transient transgenic mice with various Propl plasmids, inserts were released from the plasmid vector sequences and purified for microinjection. The 7.7-kb $\alpha G s u$-Prop $1 \triangle C E-B$ fragment was generated by digestion of the $\alpha G$ su-Prop $1 \triangle C E-B$ plasmid with Not $/ / C l a \mathrm{I}$. The $8.0-\mathrm{kb}$ $C E-B+\alpha G s u$-Prop $1 \triangle C E-B$ fragment was generated by the digestion of the $C E-B+\alpha$ Gsu-Prop $1 \Delta C E-B$ plasmid with Not $\mathrm{I} / A p a \mathrm{I}$. Both inserts were isolated by agarose gel electrophoresis and purified with the Nucleospin Extract Kit (Clontech, Mountain View, CA). Microinjection and transplantation were performed as previously reported (Cushman et al. 2001). Genomic DNA was prepared from tail biopsies of all progeny born and then screened for the transgene using the same genotyping strategy as for the aGsu-Propl (Cushman et al., 2001).
The 7-kb $C E-A / L a c Z$ fragment was generated by digestion of the $C E-A / L a c Z$ plasmid with $X h o I$. The $8.5-\mathrm{kb}$ $C E-B+C E-A / L a c Z$ plasmid was generated by digestion of the $C E-B+C E-A / L a c Z$ plasmid with NotI/ScaI. Microinjection and transplantation were performed as described above. To detect both transgenes, a 250-bp product was amplified from the genomic DNA using the Propl-specific primer (5'-GTGAGAAAACAGGTATCTAGCT-3') and the LacZ-specific primer (5'-CCACTTTGCGTTTCTTGG$\left.3^{\prime}\right)$. Reactions were performed for 33 cycles of PCR conditions: $93^{\circ} \mathrm{C}$ for $3 \mathrm{~min} \times 1,\left(94^{\circ} \mathrm{C}\right.$ for $30 \mathrm{sec}, 55^{\circ} \mathrm{C}$ for 45 sec, $72^{\circ} \mathrm{C}$ for $20 \mathrm{sec}$ ), $72^{\circ} \mathrm{C}$ for $5 \mathrm{~min}$.

All mice were housed in a 12-h light, 12-h dark cycle with unlimited access to tap water and Purina 5008 or 5020 chow. All procedures using mice were approved by the University of Michigan Committee on Use and Care of Animals, and all experiments were conducted in accordance with the principles and procedures outlined in the NIH Guidelines for the Care and Use of Experimental Animals.

Analysis of transgenic animals

Embryos were harvested on e12.5 from surrogate mothers carrying $C E-B+C E-A / L a c Z$ transient transgenics and quick frozen on dry ice. Cryosections of $12-15 \mu \mathrm{m}$ were prepared on slides and fixed in $0.5 \%$ glutaraldehyde, 1.25 mM EGTA, $2 \mathrm{mM} \mathrm{MgCl}_{2}$, and PBS (pH 7.2) for $5 \mathrm{~min}$ at room temperature, washed three times in $0.02 \% \mathrm{NP}-40$ (Amersham Pharmacia Biotech, Inc., Piscataway, NJ), 100 $\mathrm{mM}$ sodium phosphate, $2 \mathrm{mM} \mathrm{MgCl}_{2}$ wash buffer, and stained for $\beta$-galactosidase activity overnight at $37^{\circ} \mathrm{C}$ in a solution of $1 \mathrm{mg} / \mathrm{ml} \mathrm{X-gal} \mathrm{(Roche),} 5 \mathrm{mM} \mathrm{K}_{3} \mathrm{Fe}(\mathrm{CN})_{6}, 5$ $\mathrm{mM} \mathrm{K}_{4} \mathrm{Fe}(\mathrm{CN})_{6}, 2 \mathrm{mM} \mathrm{MgCl}$, and $0.02 \% \mathrm{NP}-40$ in PBS.

P1 heads from $\alpha$ Gsu-Propl, $\alpha$ Gsu-Prop $1 \Delta C E-B, C E$ $B+\alpha G s u-P r o p 1 \triangle C E-B$, and nontransgenic controls; e12.5 embryos from $C E-A / L a c Z, C E-B+C E-A / L a c Z$, and controls; or e12.5/e14.5 embryos from wild-type animals were harvested and fixed for $2-24 \mathrm{~h}$ in $4 \%$ paraformaldehyde in PBS ( $\mathrm{pH}$ 7.2) followed by PBS wash, dehydration in a graded series of ethanol, and paraffin embedding. Sixmicrometer sections were prepared on slides and washed in 0.3\% Triton X-100 (Sigma, St. Louis, MO) in PBS (pH 7.2) for $15 \mathrm{~min}$ at room temperature, permeablized by proteinase $\mathrm{K}$ digestion $(0.8 \mu \mathrm{g} / \mathrm{ml}$ in $100 \mathrm{mM}$ Tris- $\mathrm{HCl}, 50$ mM EDTA pH 8.0) for $15 \mathrm{~min}$ at $37^{\circ} \mathrm{C}$, followed by a 5min fixation in $4 \%$ paraformaldehyde in PBS (pH 7.2). To acetylate sections, tissues were exposed to $0.1 \mathrm{M}$ triethanolamine, $0.25 \%$ acetic anhydride solution for $10 \mathrm{~min}$. Tissues were prehybridized in hybridization buffer $[50 \%$ formamide, $5 \times$ SSC, $2 \%$ blocking powder (Roche Molecular Biochemicals), $0.1 \%$ Triton X-100 (Sigma), 0.5\% CHAPS (Sigma), $1 \mathrm{mg} / \mathrm{ml}$ yeast tRNA, $5 \mathrm{mM}$ EDTA (pH 8.0 ), and $50 \mu \mathrm{g} / \mathrm{ml}$ heparin]. Tissues were then hybridized 
overnight at $55^{\circ} \mathrm{C}$ with the either the Propl or $m P 1$ probe diluted in hybridization buffer.

The Propl riboprobe was generated as previously described (Cushman et al. 2001). The $m P 1$ riboprobe was generated by subcloning the $m P l$ polyA region from a modified version of the pnlacF plasmid into pBluescript $\mathrm{SK}+$ (Stratagene) at the BamHI and BglII sites (Peschon et al. 1987). The clone was linearized by digestion with BamHI to generate the antisense probe. The Propl and $m P 1$ riboprobes were generated and labeled with digoxignenin (Roche Molecular Biochemicals) following standard procedures (Mannheim 1996).

Nontransgenic P1 pituitaries were analyzed for $\alpha \mathrm{GSU}$ expression with a polyclonal rabbit anti-rat $\alpha \mathrm{GSU}$ antibody (1:1800; National Institute of Diabetes and Digestive Kidney Diseases, Torrance, CA) and detected with a biotin-conjugated anti-rabbit IgG (1:400; Vector Laboratories, Burlingame, CA) using the Vectastain ABC kit (according to manufacturer's protocol; Vector Laboratories).

PIT1 immunohistochemistry was preformed on $6-\mu \mathrm{m}$ paraffin sections of dissected pituitary tissue as described (Charles et al. 2005).

All images were captured with a Leitz DMRB microscope (W. Nuhsbaum, Inc., McHenry, IL) and an Optronics (Goleta, CA) camera.

\section{Results}

\section{PROP1 protein conservation}

In humans, PROP1 comprises three exons that encode a 226-amino-acid protein that contains a DNA-binding homeodomain and a transactivation domain at the C-terminus. Previous studies comparing the bovine PROP1 protein sequence to that of other mammals revealed that the homeodomain is highly conserved whereas the N-terminus is not (Guy et al. 2004; Showalter et al. 2002). To obtain PROP1 protein sequences from several species for comparison, we designed primers to regions of the PROPI gene sequence exhibiting high conservation between mouse and human. We used these primers to amplify genomic DNA from capuchin monkey, howler monkey, gorilla, and baboon. We sequenced the amplification products, aligned the genomic sequences, and compared them. The splice junctions are highly conserved, which permitted prediction of the cDNA and protein sequence (see Materials and methods).

Human PROP1 protein sequence was compared to the PROP1 protein sequence of various primate species, which are close relatives of humans, ranging from the hominoid primate clade, which shared a common ancestor with humans about 6-8 million years ago, to old-world and new- world monkeys which diverged approximately 25 and 40 million years ago, respectively (Nei et al. 2001; Nobrega and Pennacchio 2004). Human PROP1 protein sequence was also compared to the PROP1 protein sequence of more distantly related mammals. We selected the lemur (Lemur catta), which is a prosimian of intermediate evolutionary distance, having diverged from human about 60 million years ago (Boffelli et al. 2003), and more distantly related mammalian species such as artiodactyls and rodents, which are thought to have shared a common ancestor with humans over 80 million years ago (Nei et al. 2001; Nobrega and Pennacchio 2004). In addition, we compared partial protein sequences for nonmammalian vertebrates such as chicken and fish, which diverged from humans approximately 300 and 400-450 million years ago, respectively (Aparicio et al. 1995; Nei et al. 2001; Nobrega and Pennacchio 2004) (Table 1).

We compared the PROP1 protein sequence for 13 mammals via a clustalW alignment (Fig. 1). Previous PROP1 protein comparison illustrated high conservation within the homeodomain (Guy et al. 2004). In addition, two basic regions were identified within the homeodomain, B1 and B2, which are important for nuclear localization and DNA binding of PROP1 (Guy et al. 2004) (Fig. 1, boxed areas). The $\mathrm{B} 1$ and $\mathrm{B} 2$ regions are $100 \%$ identical between human, pig (Sus scrofa), cow (Bos Taurus), dog (Canis familiaris), mouse (Mus musculus), and rat (Rattus norvegicus) (Guy et al. 2004). Our analysis shows that the homeodomain is $100 \%$ conserved between humans, chimpanzees (Pan troglodytes), gorillas, and baboons (Fig. 1, shaded area and Table 1$)$. In fact, the homeodomain region is over $93 \%$ conserved between mouse and human (Fig. 1, Table 1) and over $93 \%$ conserved between chicken (Gallus gallus) and human (Table 1). Even very distantly related vertebrate fish such as fugu (Fugu rubripes) and zebrafish (Danio rerio) show extensive conservation with human in the PROP1 homeodomain region (Table 1). Although we were surprised that the predicted fish proteins are much more divergent from the mammalian proteins than the bird (chicken), an extensive cladistic analysis of the paired domains of fish and mammalian genes support the idea that the fish sequences we present are the likely orthologs of the mammalian sequences (data not shown). In addition, all of the species that we analyzed had $100 \%$ identity in the B1 and $\mathrm{B} 2$ regions with the exception of the chicken, in which only partial sequence was available (data not shown), and the lemur, which had an in-frame deletion of R71 (Fig. 1, indicated by white box). This is consistent with the expectation that the homeodomain region is an important functional region of the PROP1 protein because it has evolved slowly compared to the other domains. To date all of the mutations in the human population that are known to cause MPHD as a result of PROP1 deficiency are predicted 
Table 1 The PROP1 homeodomain is highly conserved among vertebrate species

\begin{tabular}{|c|c|c|c|c|c|c|c|}
\hline & \multirow[t]{2}{*}{ Description } & \multirow[t]{2}{*}{ Organism } & \multirow{2}{*}{ 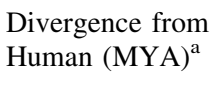 } & \multicolumn{4}{|c|}{ PROP1 Protein Comparison (\% ID to Human) } \\
\hline & & & & N-terminus & Homeodomain & Transactivation & Total protein \\
\hline \multirow[t]{12}{*}{ Mammals } & Hominoid & Chimpanzee & $6-8$ & 100 & 100 & 96.9 & 98.7 \\
\hline & & Gorilla & & 95.6 & 100 & 98 & 97.4 \\
\hline & Old-world & Baboon & $\sim 25$ & 91.2 & 100 & 95.9 & 95.6 \\
\hline & New-world & Howler & $\sim 40$ & 77.9 & 98.3 & 89.8 & 88.5 \\
\hline & & Capuchin & & 80.9 & 98.3 & 87.8 & 88.5 \\
\hline & Prosimian & Lemur & $\sim 60$ & 66.2 & 90 & 84.7 & 80.2 \\
\hline & Artiodactyl & Pig & $\sim 80$ & 66.2 & 96.7 & 82.7 & 81.5 \\
\hline & & Cow & & 47.1 & 96.7 & 80.6 & 74.9 \\
\hline & & Sheep & & 50 & 95 & 81.6 & 75.3 \\
\hline & Carnivore & Dog & & 57.4 & 93.3 & 85.7 & 79.3 \\
\hline & Rodent & Rat & & 51.5 & 90 & 71.4 & 70 \\
\hline & & Mouse & & 48.5 & 93.3 & 76.5 & 72.7 \\
\hline \multirow[t]{4}{*}{ Non-mammals } & Bird & Chicken & $\sim 300$ & $\mathrm{n} / \mathrm{a}^{\mathrm{b}}$ & $93.6^{\mathrm{c}}$ & 69.4 & $\mathrm{n} / \mathrm{a}$ \\
\hline & Fish & Fugu & $400-450$ & $\mathrm{n} / \mathrm{a}$ & 81.7 & 25.5 & $\mathrm{n} / \mathrm{a}$ \\
\hline & & Zebrafish & & $\mathrm{n} / \mathrm{a}$ & 76.7 & 26.5 & $\mathrm{n} / \mathrm{a}$ \\
\hline & & Tetraodon & & $\mathrm{n} / \mathrm{a}$ & 78.3 & 29.6 & $\mathrm{n} / \mathrm{a}$ \\
\hline
\end{tabular}

to eliminate function of the homeodomain, with the exception of the recently discovered nonsense mutation that occurs in the transactivation domain. The homeodomain mutations include various missense mutations (Fig. 1) as well as deletions, truncations, nonsense mutations, and splicing mutations (Cushman and Camper 2001; Parks et al. 1999; Reynaud et al. 2005). The homeodomain also contains the point mutation of the Ames dwarf mouse (Sornson et al. 1996) (Fig. 1). The transactivation domain is also well conserved among mammals, ranging from approximately 97\%-98\% identity between human and other hominoids to $76.5 \%$ identity between human and mouse (Fig. 1, Table 1). The N-terminus is the least conserved domain of PROP1, with only approximately $80 \%$ and approximately $78 \%$ identity between human and the closely related capuchin and howler primates, respectively, and less than $50 \%$ identity between human and mouse (Fig. 1).

There are polymorphisms that occur within the PROP1 protein of humans, as well as in that of sheep, mice, and cows. (Fig. 1). Allelic variants occur in the transactivation domain in sheep (Ovis aries), T181A (Guy et al. 2004), cow, H173R (Showalter et al. 2002), and mouse, G155A, S171A, and 208/ $209 \mathrm{P}$ insertion (Sornson et al. 1996). There is also a mouse polymorphic deletion of one CA within a CA repeat in the mouse UTR (Sornson et al. 1996). The human polymorphisms S20N, A51G, and G60E are located in the N-termi- nus, while A142T (Nakamura et al. 1999b), is located in the transactivation domain. The 21 additional human polymorphisms located in the noncoding sequence and silent mutations within exons 1 and 2 are listed at the SNP NCBI site (http://www.ncbi.nlm.nih.gov/). Although none of these polymorphisms have been implicated in disease, they may play a role in the genetic variation of quantitative traits within the animal kingdom.

\section{PROP1 sequence comparison reveals three conserved noncoding elements}

Previous studies using $5^{\prime}$ RACE located the human PROPI transcription initiation site 309 nucleotides upstream of the translation initiation site (Duquesnoy et al. 1998). We predicted the transcription initiation site of the mouse Propl by comparing the mouse genomic sequence with the consensus $5^{\prime}$ sequence of four mouse Propl cDNA clones obtained from full-length cap-trapper cDNA libraries (Carninci et al. 2003). This revealed that the transcription initiation site is located 353 nucleotides upstream of the translation start site. This is 126 nucleotides upstream of the previous transcription initiation site annotated by the GenBank sequence NM008936 (http://www.ncbi.nlm.nih.gov/). Our results indicate a similar length for the human and mouse $5^{\prime}$ UTR, but the sequence of this region is poorly conserved (data not shown). 
Fig. 1 PROP1 protein comparison reveals lack of conservation in the amino terminal domain. The PROP1 protein sequence alignment for 12 mammals shows very high conservation in the

homeodomain region (shaded area) and in the transactivation domain in the carboxy terminus. The $\mathrm{B} 1$ and $\mathrm{B} 2$ regions within the homeodomain are boxed. The white box indicates the deleted amino acid within the B1 domain of the lemur. Mutations in those amino acids within the homeodomain region that are known to cause MPHD in humans $(*)$ and mice (\#) are indicated. Allelic variants in the sheep (\$), cow (!), mouse (+), and human $(\wedge)$ are indicated. Human SNPs for PROP1 were obtained from NCBI website (http://www.ncbi.nlm.nih.gov/). Arrows indicate the exon boundaries. E1, exon 1; E2, exon 2; E3, exon 3

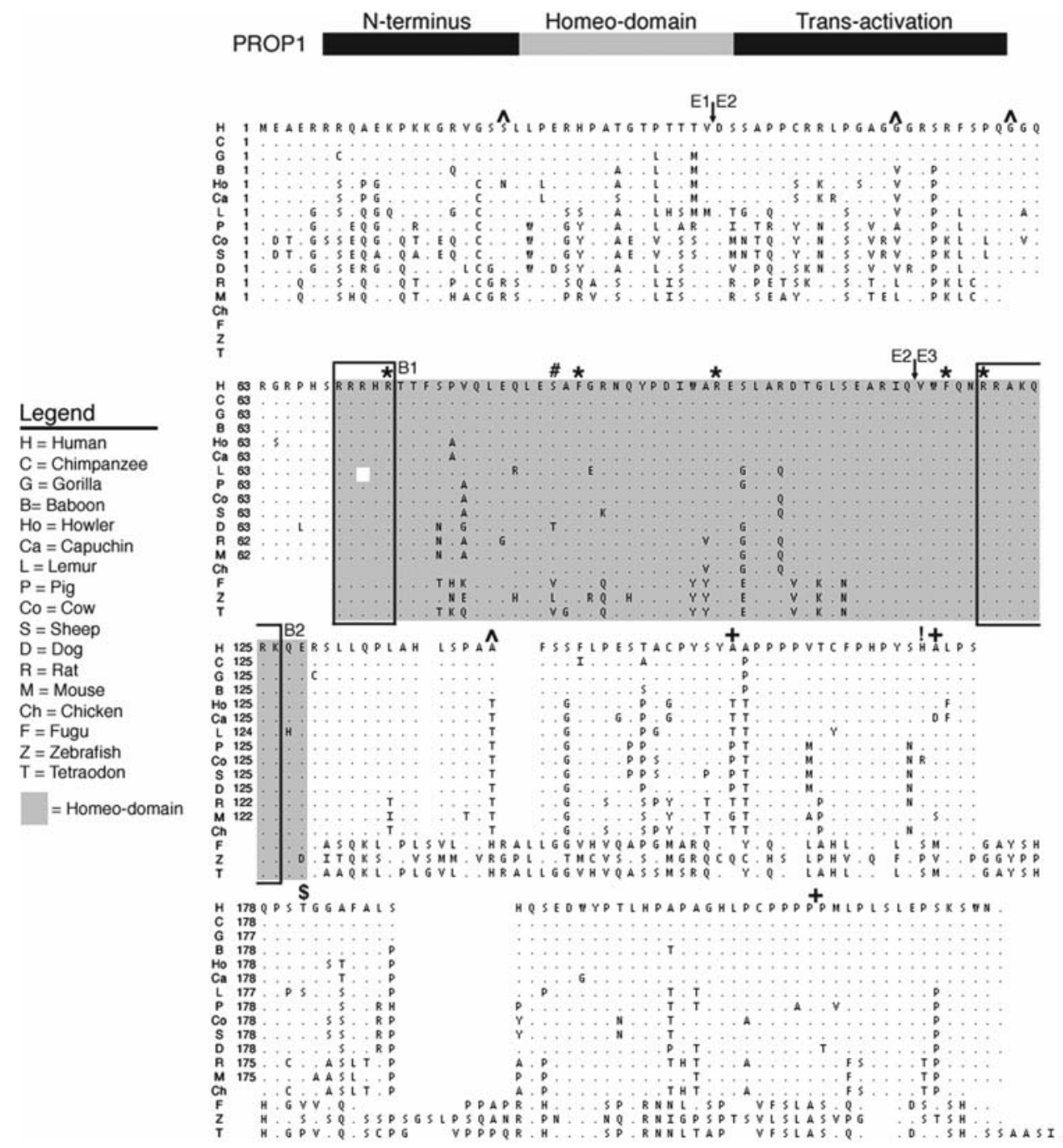

We compared the 5q35.3 chromosome region containing human $P R O P 1$ with the orthologous region in mouse using the UCSC genome browser (http://www.genome.ucsc.edu/), (Fig. 2A) (Kent et al. 2002). The nearest known 5' neighboring gene to $P R O P 1$ is $N 4 B P 3$, located $118 \mathrm{~kb}$ upstream of $P R O P 1$, and the nearest known $3^{\prime}$ neighboring gene, $A K 126616$, is $34 \mathrm{~kb}$ downstream. In comparison, the nearest $5^{\prime}$ and $3^{\prime}$ genes to the mouse Propl gene are located $15 \mathrm{~kb}$ (Olfr1378) and $7 \mathrm{~kb}$ (4933414115Rik) in distance, respectively. This analysis also reveals that the mouse genomic region orthologous to the approximately $620-\mathrm{kb}$ flanking region $5^{\prime}$ of the human $P R O P 1$ gene is inverted and separated from mouse Propl by a series of olfactory genes that map to human chromosomes 16 and 17 (Fig. 2A, lined box). An approximately $760-\mathrm{kb}$ region located approximately $750 \mathrm{~kb}$ $5^{\prime}$ to the human PROP1 gene is present in the reverse orientation $3^{\prime}$ to the mouse Propl gene (Fig 2A, gray box). Additional comparisons of the Propl locus between human and chimpanzee and between rat and mouse reveal gene order conservation among primates and among rodents (data not shown). A genome VISTA comparison of the pig Propl BAC to the mouse genome indicated gene order conservation (Couronne et al. 2003), suggesting that the region surrounding the pig Propl locus is more similar to the mouse Propl locus than to the human (Fig. 2B). These disruptions in the gene order between the orthologous regions surrounding the human and mouse or pig PROPl genes may obscure the identification of conserved elements located at great distances from the gene, but comparative genomics is useful for the identification of putative regulators within 26 $\mathrm{kb}$ that extends $5^{\prime}$ and $3^{\prime}$ from mouse Propl to the nearestneighboring genes.

To determine whether all of the elements necessary for appropriate regulation of Propl transcription are contained within a reasonably close distance to the gene, we sought to rescue the Propl dwarf phenotype using a mouse BAC containing Propl. Propl mutants have profound, proportional dwarfism evident within the first two weeks of life, and adult mutants are approximately one third the size of their normal littermates (Buckwalter et al. 1991). Further- 


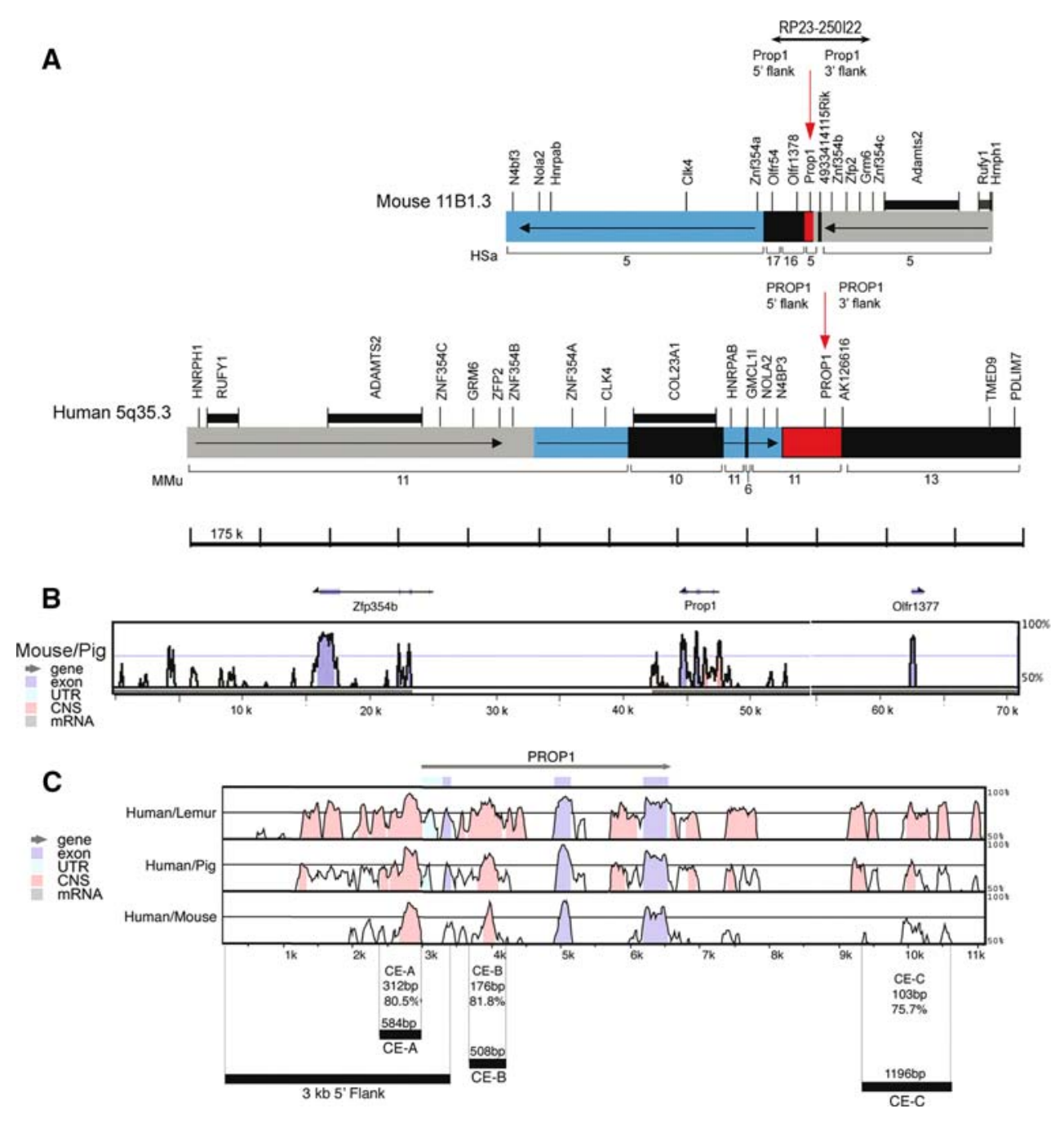

Fig. 2 Mammalian genomic DNA sequence comparisons reveal the presence of several highly conserved elements. A The approximate position of BAC RP23-250122, used for transgene correction of the Prop1-deficient phenotype, is indicated at the top (double arrow), aligned with the genome sequence from the mouse. Orthologous regions of the human chromosome $5 \mathrm{q} 35.3$ and the mouse chromosome 11B1.3 reveal disruptions in gene order. An approximately 760$\mathrm{kb}$ region that is about 750 upstream of human PROP1 is inverted and located approximately $10 \mathrm{~kb} \mathrm{3'}$ of the mouse Propl (gray box, arrow). An approximately $620-\mathrm{kb}$ region $5^{\prime}$ to the human $P R O P 1$ is inverted

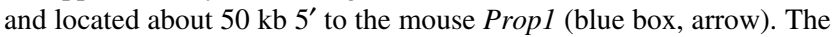
nearest genes $5^{\prime}$ and $3^{\prime}$ to both the human and the mouse PROPI genes are shown. Large genes are indicated by black bars. The PROP1 gene locus is indicated by the red box and red arrow. Scale bar is marked in 175 kilobase $(\mathrm{kb})$ increments. The arrow indicates the orientation of the PROP1 gene. MMu, mouse orthologs to the human $5 \mathrm{q} 35.3$ are indicated by a bracket and mouse chromosome

more, their pituitaries have little or no GH, TSH, and PRL and exhibit anterior lobe hypoplasia and overall pituitary dysmorphology (Gage et al. 1996b; Nasonkin et al. 2004; Ward et al. 2005). The mouse BAC RP23-250I22 is about $195 \mathrm{~kb}$ long and contains genomic sequence extending from within the Olfr54 gene at the 5' end of Propl to the number. HSa, human orthologs to the mouse 11B1.3 are indicated by a bracket and human chromosome number. B Genome VISTA plot comparing the pig Prop1 BAC to the mouse genome revealing gene order conservation. Colored peaks represent greater than $75 \%$ identity over 100 bp. The mouse Zfp354b, Propl, and Olfr1378 genes are indicated by the arrows. C Pairwise comparisons are presented for human vs. lemur, pig, and mouse. Colored peaks represent greater than $75 \%$ identity over $100 \mathrm{bp}$. The regions of gene used for the analysis of the conserved noncoding regions are indicated by the black bars and dotted lines below the respective peaks. The PROPI gene is indicated by the gray arrow. B, C $x$-axis, kilobases; $y$-axis, percent identity ranging from $50 \%$ to $100 \%$. Light blue, untranslated regions (UTR); dark blue, coding regions; pink, conserved noncoding regions; bp, base pairs; $\mathrm{CE}-\mathrm{A}$, conserved noncoding element $\mathrm{A}$; $\mathrm{CE}-$ $\mathrm{B}$, conserved noncoding element $\mathrm{B}$; $\mathrm{CE}-\mathrm{C}$, conserved noncoding element C (URL: http://www-gsd.lbl.gov/VISTA/)

Znf354c gene at the $3^{\prime}$ of Propl (Fig. 2A, double arrow). Therefore, this BAC contains additional sequence and predicted genes past the immediate-neighboring genes for Propl. We injected this BAC into pronuclei of eggs derived from a cross of wild-type and Prop $^{+/ d f}$ mice. Seven transgenic lines were established, of which three were 
founded by Propl $^{+/ d f}$ mice and four by Propl $^{+/+}$mice. Two BAC transgenic Propl $^{+/+}$lines were crossed to Propl ${ }^{+/ d f}$ mice to generate additional lines of BAC transgene; Propl $^{+/ d f}$. These transgenic heterozygotes were crossed to Prop $^{+/-}$mice to generate BAC transgene; Prop $I^{\mathrm{df} /-}$ mice and other assorted genotypes. Propl ${ }^{\mathrm{d} f /}$ mice that harbor the Prop1-containing BAC did not have a dwarf phenotype but instead were equivalent in size to Propl $^{+/+}$and Propl $I^{+/-}$ littermates (Fig. 3A, B). Of the five BAC transgenic lines tested, three produced multiple offspring $(n=2-4)$ in which the presence of the BAC rescued the Propl ${ }^{\mathrm{df} /-}$ dwarf phenotype. Among these lines there were no cases of BAC transgene; Prop ${ }^{\mathrm{df} /-}$ mice that were smaller than normal. One line produced multiple offspring $(n=2)$ in which the presence of the BAC did not rescue the Propl ${ }^{\mathrm{df} /-}$ dwarf phenotype, suggesting that the BAC was not intact or integrated in a region of the genome incompatible with functionally appropriate expression. One line did not produce the desired combination of the BAC transgene with Prop $^{\mathrm{df} /-}$ in 30 pups examined, suggesting that the BAC integrated on chromosome 11.

The BAC transgene; Propl ${ }^{\mathrm{df} /-}$ mice exhibiting phenotypic rescue of body size have a pituitary gland morphology indistinguishable from that of wild-type littermates, while nontransgenic Prop $1^{\mathrm{df} /-}$ mice have obviously hypoplastic anterior lobes (Fig. 3C). In addition, the BAC transgene; Prop ${ }^{\mathrm{df} /-}$ pituitaries contained cells that express PIT1 (Fig. 3D-F), GH, PRL, and TSH (data not shown), which are essentially absent in the $P$ rop $I^{\text {df/- }}$ dwarf pituitaries. Therefore, the Propl-containing BAC is able to restore the pituitary cell types that are absent in the pituitaries of Propl ${ }^{\mathrm{df} /}$ - mice, as well as pituitary size, somatic growth, and function of pituitary target organs.

We compared a $20-\mathrm{kb}$ region of the human PROPI genomic sequence with similar portions of genomic DNA from three mammalian species: lemur, pig, and mouse. We discovered regions in the noncoding sequence of $P R O P 1$ that are highly conserved over evolutionary time (Fig. 2C). Approximately $10 \mathrm{~kb}$ of this sequence overlapped in all four mammals and was analyzed by the mVISTA sequence comparison program (Bray et al. 2003), which displays regions of sequence conservation between two species that are at least $100 \mathrm{bp}$ long with $75 \%$ identity (Fig. 2C). The human PROPl gene is approximately $4 \mathrm{~kb}$ long and is located in a region of the genome that contains relatively few genes. Exons 2 and 3, which encode the HD and TA domains (Fig. 1), are highly conserved among all four species (Fig. 2C, blue peaks). Exon 1, however, is relatively divergent among these species (Fig. 2C). The mVISTA plot also reveals three conserved noncoding sequences among human, lemur, pig, and mouse (Fig. 2C, pink peaks). The first conserved element $\mathrm{A}(C E-A)$ is located in the $5^{\prime}$ flanking sequence $9 \mathrm{bp}$ upstream of the mouse transcription initiation site and is $80.5 \%$ identical between human and mouse over 312 bp (Fig. 2C). $C E-B$ is located within intron 1 of Propl and is $81.8 \%$ identical
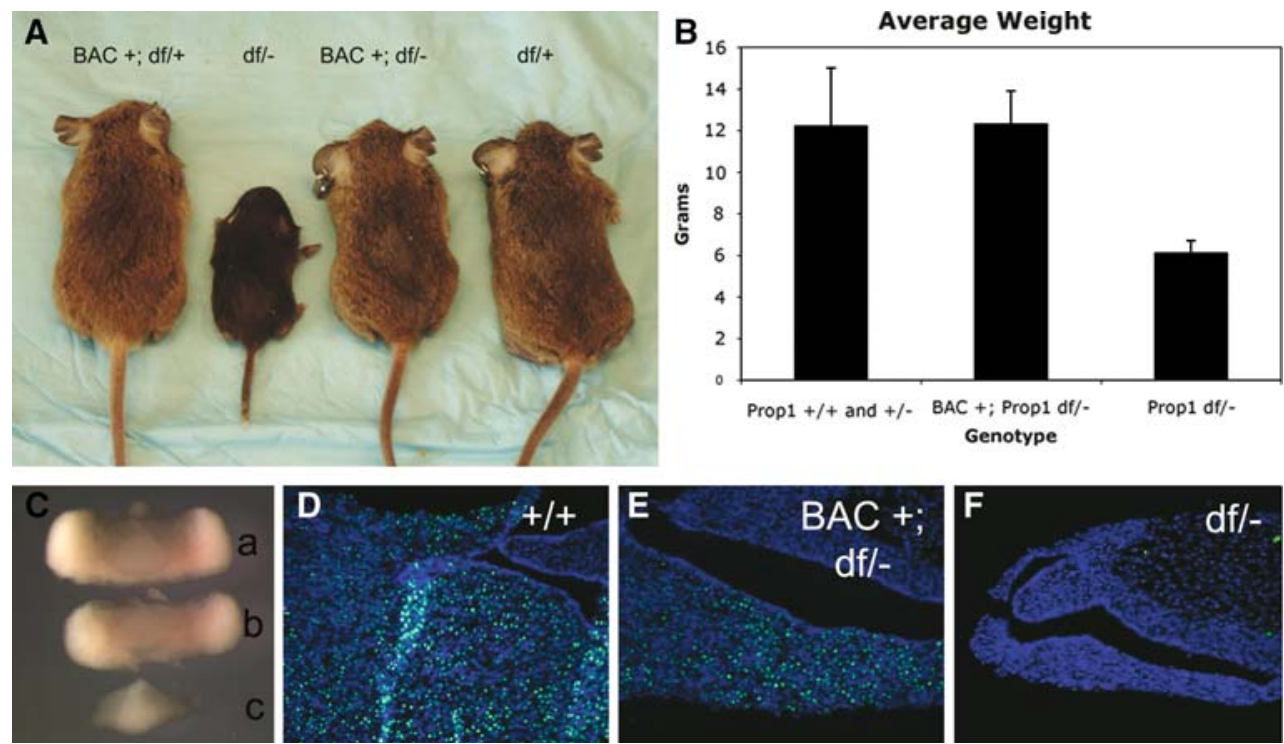

Fig. 3 A Prop1 BAC transgene rescues the Prop1 mutant phenotype. A Four sample mice and corresponding genotypes. Prop $I^{\mathrm{df} /-}$ mice are dwarf, but the presence of the BAC transgene rescues the dwarf phenotype. B The average weight of mice of each genotype is graphed for all progeny of a cross of BAC transgenic; Prop $1^{\mathrm{df} /}$ ${ }^{+} \times$Prop $^{+/-}$. Error bars represent the standard deviation. For Prop ${ }^{+1}$ ${ }^{+}$and Prop $^{+/-}$mice, 116 mice were weighed at weaning, while 19 and 11 were weighed for $\operatorname{Prop}^{\mathrm{df} /-}$ and BAC transgenic; Propl ${ }^{\mathrm{df} /-}$, respectively. C Dissected pituitaries from P21 mice. The genotypes are as follows: $\mathrm{a}=$ Propl $^{+/+}, \mathrm{b}=\mathrm{BAC}$ transgenic; Propl ${ }^{\mathrm{df} /-}$, $\mathrm{c}=$ Prop ${ }^{\mathrm{d} f /}$. D-F PIT1 immunohistochemistry. The genotypes for each image are as follows: D Prop ${ }^{+/+}$, E BAC transgenic; Propl ${ }^{\mathrm{df} /-}$, F Propl $1^{\mathrm{df} /-}$ 
between human and mouse over 176 bp (Fig. 2C). The third conserved region, $C E-C$, is the smallest conserved noncoding element and is only $75.7 \%$ identical between human and mouse with a length of approximately $100 \mathrm{bp}$ (Fig. 2C).

The Propl CE-A and CE-B regions show enhancer activity in tissue culture

Various in vitro and in vivo methods have been used to test the biological function of conserved elements discovered by comparative genomics (Boffelli et al. 2003; Lettice et al. 2003; Nobrega et al. 2003; Zerucha et al. 2000). CE-A has no promoter activity in a heterologous CV1 monkey kidney or the $\alpha \mathrm{T} 3$ mouse gonadotrope-like cell lines (data not shown). Therefore, $C E-A, C E-B$, and $C E-C$ were analyzed for enhancer activity in tissue culture by inserting each of them in both the forward and the reverse orientation upstream of the Drosophila alcohol dehydrogenase $(A D H)$ minimal promoter driving a luciferase (Luc) reporter gene (Fig. 4A, construct \#1). The cell lines used for the transfection assays included the $\mathrm{CV}-1, \alpha \mathrm{T} 3, \mathrm{GH} 3$ rat somatotrope-like, and AtT-20 mouse corticotrope-like cell lines. The enhancer activity of these elements is reported as the fold increase in luciferase activity over the basal level of the $A D H$-Luc vector alone.

A 584-bp Propl 5' flanking segment containing the $C E$ $A$ element from the mouse Propl gene was cloned into the $A D H$-Luc vector in both forward and reverse orientations (Figs. 2C and 4A, constructs \#2 and \#3, respectively). On average, the $C E-A(F) / A D H$ construct displayed about a 13.5-fold increase in activity in the CV-1 cells and approximately 4-5-fold increase in activity in the GH3, $\alpha \mathrm{T} 3-1$, and AtT-20 cell lines (Fig. 4B). When the $C E-A$ was tested in the reverse orientation (Fig. 4A, construct $\# 3)$, the $C E-A(R) / A D H$ showed no activity in any of the cell lines tested, indicating that the effect is orientationdependent (Fig. 4B).

A 508-bp segment from intron 1 of the mouse Propl gene containing the $C E-B$ element was also tested for enhancer activity in the $A D H-L u c$ reporter construct (Figs. 2C and 4A, constructs \#4 and \#5, respectively). The $C E-B(F) / A D H$ construct elicited, on average, a fourfold increase in luciferase activity compared to the $A D H-L u c$ alone in the CV-1 cells (Fig. 4B). However, the $C E-B(F)$ / $A D H$ had very low activity in the GH3 cells (less than a twofold average increase over basal with a range of 1.12.6-fold) and no activity in either the $\alpha \mathrm{T} 3-1$ or the AtT-20 lines (Fig. 4B). The $C E-B(R) / A D H$ construct showed no enhancer activity in any of the cell lines tested (Fig. 4B).

A 1196-bp segment from the $3^{\prime}$ flanking sequence of the mouse Propl gene containing $C E-C$ was inserted into the $A D H-L u c$ reporter construct (Figs. $2 \mathrm{C}$ and $4 \mathrm{~A}$, constructs
\#6 and \#7, respectively). A larger section was used in the analysis of the $C E-C$ element because there were several smaller peaks on the mVISTA plot between human and mouse that showed significant conservation between human and pig and between human and lemur that flanked the $C E-C$ segment (Fig. 2C). The $C E-C$ in either orientation appeared to have no enhancer activity in the $\alpha \mathrm{T} 3-1$ or the GH3 cell lines but did have a low level of activity in the forward orientation when tested in the CV-1 and AtT-20 cell lines (Fig. 4B).

In summary, the $5^{\prime}$ element $C E-A$ had the highest activity with the $A D H-L u c$ reporter. The $C E-B$ intronic element and the $C E-C 3^{\prime}$ element had low orientationdependent enhancer activity in the CV-1 cells and very low, if any, activity in the pituitary-derived cell lines. This was not surprising because these pituitary cell types are derived from differentiated pituitary cells and do not express endogenous Propl. These pituitary-like cells may not have all the components necessary to allow for the proper function of all of the Propl enhancer elements or they may contain factors that repress the function of these elements.

\section{The Propl CE-A element is not sufficient for LacZ expression in transgenic mice}

The $C E-A$ and $C E-B$ regions were also analyzed in transgenic mice to determine whether they function in vivo. $C E$ A/LacZ (Table 2), which consists of a $3-\mathrm{kb}$ region immediately $5^{\prime}$ to the Propl ATG containing the $5^{\prime}$ UTR, the Propl transcription initiation site, and the $C E-A$ region, was analyzed for the ability to drive the expression of a nuclear localized $E$. coli $\beta$-galactosidase-mouse protamine 1 reporter construct $(L a c Z-p A)$ in transgenic mice (Fig. 2C). Transgenic founders were bred to produce lines for embryo analysis, or transient transgenic embryos were harvested and analyzed for the transgenic transcript via in situ hybridization (ISH) at e12.5 because this is the time of peak Propl expression (Sornson et al. 1996). We used the well-characterized $\alpha$ Gsu-LacZ and $\alpha$ Gsu-Propl transgenes as positive controls for detecting $\beta$-galactosidase activity in the pituitary gland by $\mathrm{X}$-gal staining and for mouse protamine ISH, respectively (Cushman et al. 2001; Kendall et al. 1994). The promoter and enhancer sequences of the pituitary glycoprotein hormone $\alpha$-subunit gene ( $\mathrm{Cga}$ for chorionic subunit $\alpha$ or $\alpha G s u$ ) are sufficient to drive expression of $L a c Z$ and other reporters in a manner that is developmentally, hormonally, and tissue-specifically correct (Kendall et al. 1994). Both the $\alpha$ Gsu-LacZ transgenic mice and the $\alpha$ Gsu-Propl transgenic mice contain the mouse protamine splice sites and polyadenylylation sequences that can be used as a transgene-specific tag in any organ except the testis, which expresses the endogenous protamine gene. None of the five transgenic embryos 
Fig. 4 Enhancer study of Prop1 conserved noncoding elements from the mouse gene in monkey kidney CV-1, GH3 (rat somato-lactotropes), $\alpha \mathrm{T} 3-1$ (mouse gonadotrope-like), and AtT-20 (mouse corticotropelike) cells. A Diagram of the conserved elements upstream of the $A D H-L u c$ reporter construct. B Luciferase activity as fold activation over basal shown for the constructs depicted in (A) for $\mathrm{CV}-1, \mathrm{GH} 3$, $\alpha \mathrm{T} 3-1$, and AtT-20 cells reveal orientationdependent enhancer activity for $C E-A$ in all lines and for $C E-B$ in $\mathrm{CV}-1$ and GH3 lines. ADH, alcohol dehydrogenase minimal promoter; LUC, luciferase reporter gene; $\mathrm{F}$, forward orientation; $\mathrm{R}$, reverse orientation. The asterisk designates constructs with activity significantly above baseline
A
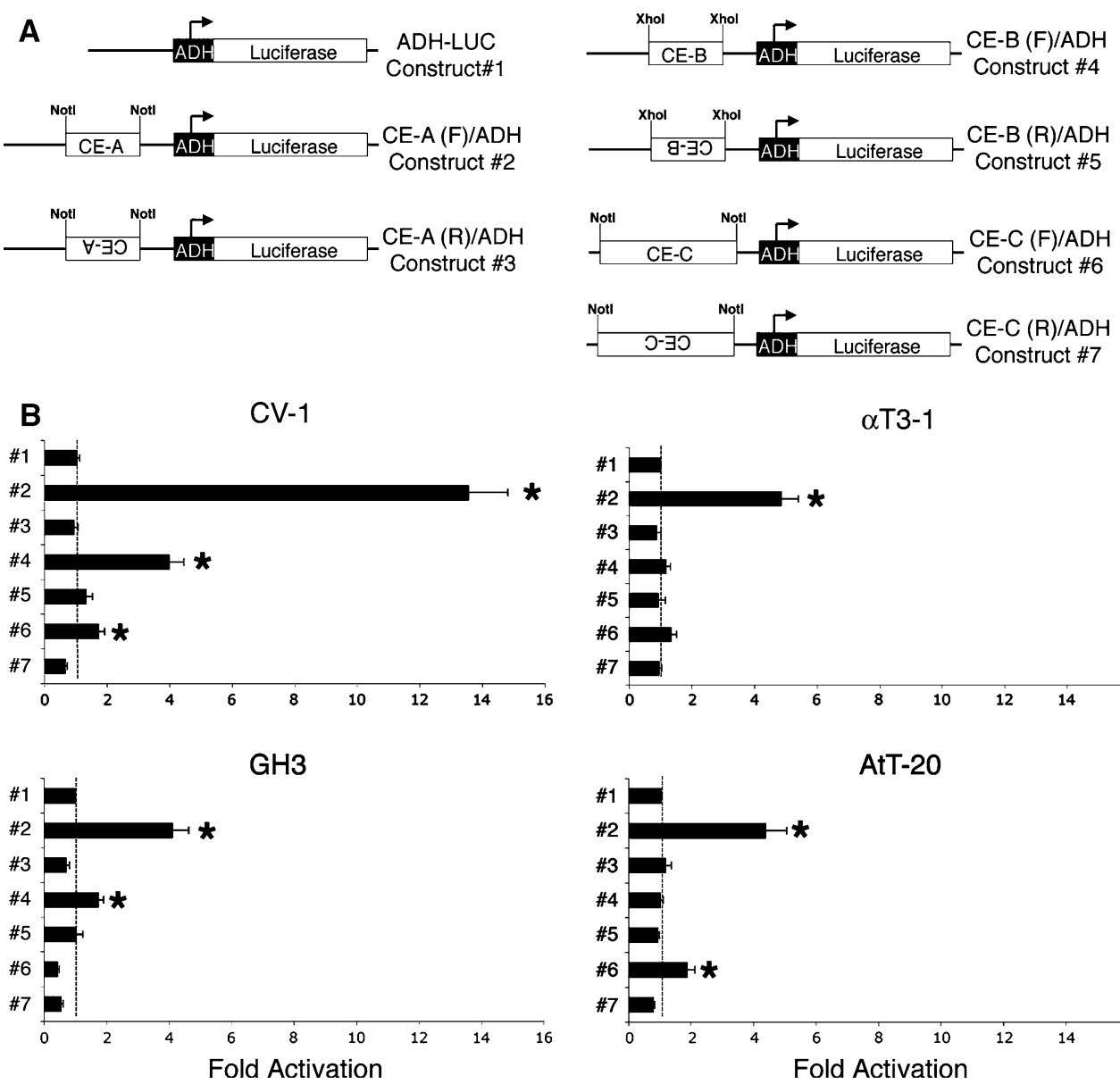

$\alpha T 3-1$

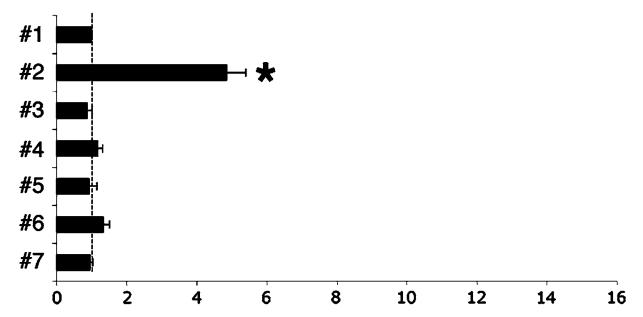

AtT-20

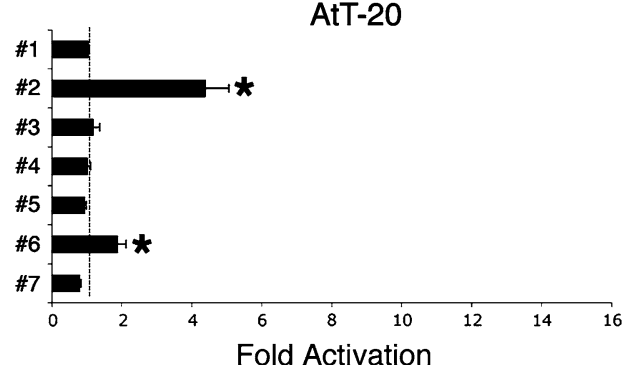

exhibited detectable transcription of the $C E-A / L a c Z$ transgene compared with positive controls. Thus, the 3-kb 5' flanking region of Propl is not sufficient for transgene expression. The intronic $C E-B$ element was tested in conjunction with $C E-A$ for in vivo Propl expression. Transgenic mice were made with the construct $C E-B+C E-A$ / $L a c Z$, which contains $C E-B$ upstream of the Propl 3-kb 5' flanking region (Fig. 2C, Table 2). Fifteen transient transgenic embryos were harvested at e12.5 and assayed for expression of the transgene by either X-gal staining or ISH for $m P 1$. None of the 15 embryos analyzed had detectable expression of the transgene, although the positive controls did exhibit expression. Thus, the combination of $C E-B$ and $C E-A$ is also not sufficient for expression in vivo.

\section{The Propl CE-B putative enhancer is important for spatial expression in transgenic mice}

The $C E-B$ region was tested for enhancer function in transgenic mice in the context of the $\alpha G s u$ promoter. The first clues to a possible role for $C E-B$ in the expression of Propl came from the analysis of the $\alpha$ Gsu-Propl transgenic mice (Table 2). Endogenous Propl is normally expressed from e9 until e15.5 in the mouse in a dorsal (highest) to ventral (lowest) expression gradient (Fig. 5A) (Sornson et al. 1996). In contrast, $\alpha G s u$ is expressed during pituitary development in the caudomedial and ventral portions of the pituitary where the thyrotropes and gonadotropes arise, and its expression continues in these two cell types throughout adulthood (Fig. 5B) (Japon et al. 1994; Kendall et al., 1994; Raetzman et al. 2002). Ten stable lines were created with the $\alpha$ Gsu-Propl transgene and six expressed the transgene in the adult pituitary. Two lines were maintained and analyzed (Cushman et al. 2001). These studies revealed that the $\alpha$ Gsu-Propl construct yields efficient overexpression of Propl beyond e15.5 (Cushman et al. 2001). Expression of the $\alpha$ Gsu-Propl transgene is expanded dorsally beyond the normal expression domain of endogenous $\alpha G s u$ and beyond that observed for other $\alpha G s u$ driving expression of LacZ or other reporters. This dorsal expression is observed in pituitaries at postnatal day 1 ( $\mathrm{P} 1$, day of birth) in $2 / 2$ stable transgenic lines and at e18.5 in $3 / 3$ transient transgenics that were created with the same $\alpha$ Gsu-Propl construct. This expression pattern appears to be a combination of both endogenous $\alpha$ Gsu and Propl (compare Fig. 5C with B and A). This result suggests that the $C E-B$ region is important for the dorsal expansion of the $\alpha G s u$-Propl transgene and 
Table 2 Transgenic constructs used to test the in vivo function of the conserved non-coding elements of the mouse Prop 1 gene

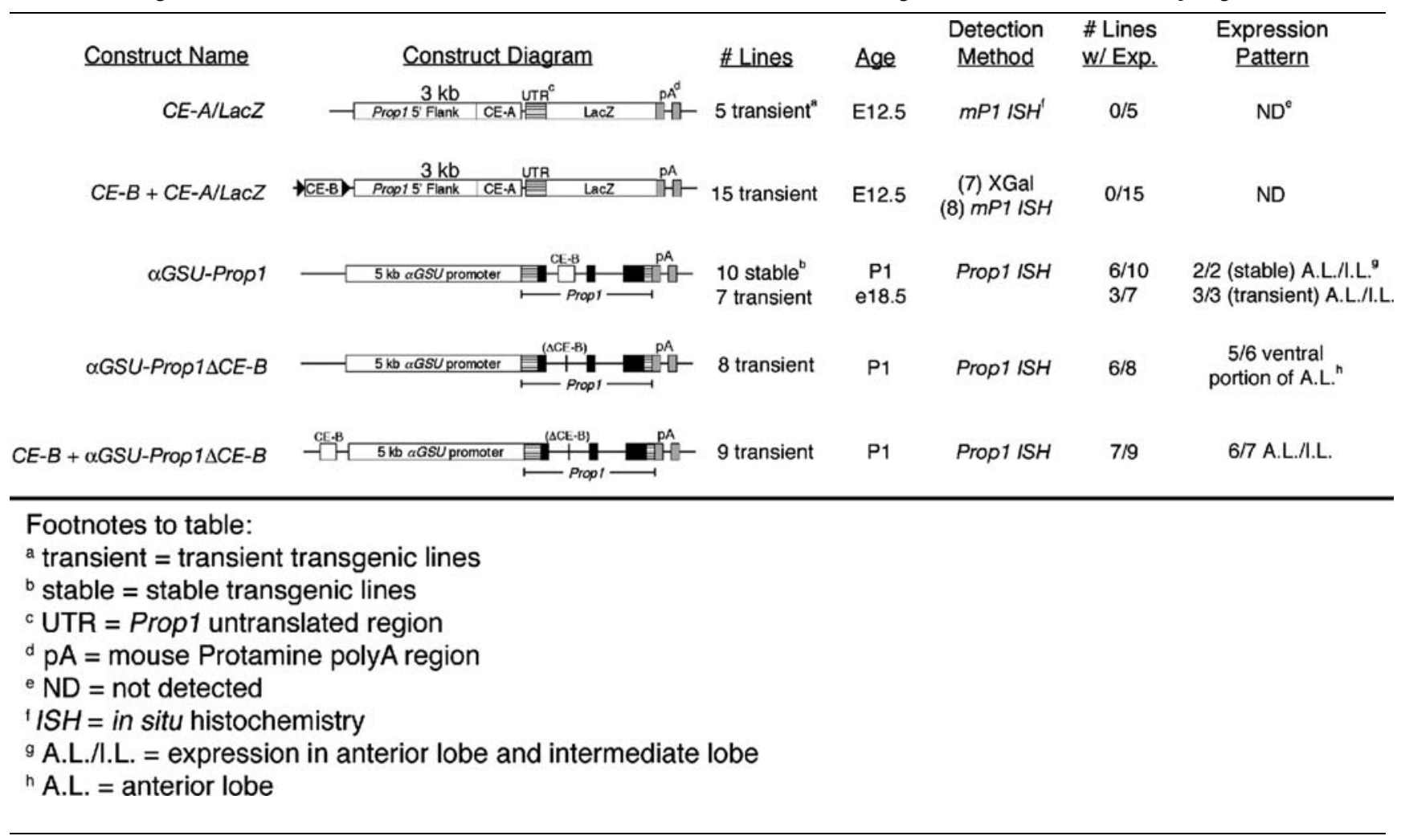

thus important for the spatial expression of endogenous Propl.

We tested the significance of $C E-B$ for dorsalized transgene expression by deleting $C E-B$ from intron 1 to produce the construct $\alpha$ Gsu-Propl $\triangle C E-B$ (Table 2). Transient transgenics bearing this construct were harvested at P1 and assayed for the expression of the transgene using ISH for Prop1. Six of the eight transgenic mice analyzed exhibited transgene expression. One had very weak expression and was eliminated from further consideration. The remaining five had strong expression. In these five transgenic mice, the expression pattern of the $\alpha$ Gsu-Prop $1 \Delta C E-B$ transgene is restricted to the ventral aspects of the pituitary, typical for the $\alpha G s u$ promoter and enhancer (compare Fig. $5 \mathrm{D}$ with $\mathrm{C}$ ). This result indicates that $C E-B$ was necessary for the dorsal expression of the $\alpha$ Gsu-Propl construct.

To determine whether the position of the $C E-B$ relative to the $\alpha G s u$ promoter is critical, the $C E-B$ region was replaced in the $\alpha G s u$-Prop $1 \Delta C E-B$ construct upstream of the $\alpha G s u$ promoter to create a new construct, $C E-B+\alpha G s u$ Prop $1 \triangle C E-B$ (Table 2). The $C E-B+\alpha G s u-P r o p 1 \triangle C E-B$ transgenic mice were harvested at P1 and assayed for expression of the transgene. The $C E-B+\alpha G s u-P r o p l \Delta C E-$ $B$ transgene expression was expanded to the dorsal aspect of the pituitary in six of seven transient lines (Fig. 5E), with the remaining line having only weak expression of the transgene. Finally, an ISH for Propl on nontransgenic pituitaries gave no signal (Fig. 5F), thus verifying that the patterns of expression seen in Figs. 5C, D, F are due to the specific transgene. The transgenic analysis provided in vivo evidence that the $C E-B$ contained within the intron 1 of Propl is sufficient to confer spatial expression information in a position-independent manner in the context of the transgene.

\section{Discussion}

We sought to identify cis-acting DNA sequences important for mouse Propl expression because regulation of Propl is important for normal pituitary development and function. To accomplish this, we obtained genomic sequence from lemur and pig (Sus scrofa) PROP1 BACs and compared these to PROP1 sequences available online (Ahituv et al. 2004; Aparicio et al. 1995; Boffelli et al. 2003, 2004; Nobrega and Pennacchio 2004; Williams et al. 2003). We also generated PROP1 genomic sequence for the first time for five different primate species to include in the comparison. We identified three conserved noncoding elements (CE) that are larger than $100 \mathrm{bp}$ with greater than $75 \%$ identity between human and mouse and tested them for function in cell culture and transgenic mice. The three re- 
gions that fit these criteria are $C E-A$, a 300-bp region in the Propl promoter proximal region; $C E-B$, a 200-bp region within the first intron of Propl; and $C E-C$, a 103-bp region within the $3^{\prime}$ flanking sequence.

Transfection of cultured cells has been successful for demonstrating the function of some elements (Nishimura et al. 2000; Surinya et al. 1998; Swamynathan and Piatigorsky 2002), but there are examples of important regulatory sequences that are not identified with this approach
(Lang et al. 2003; Lettice et al. 2003; Nobrega et al. 2003; Zerucha et al. 2000). Propl is expressed in a distinct spatial-, temporal-, and tissue-specific fashion during development, and the endogenous gene is not expressed in any of the available pituitary cell lines. Nevertheless, $C E-A$ exhibited orientation-dependent activity in all cell lines. $C E-B$, located within intron 1 of Propl, also appeared to have orientation-dependent enhancer activity in CV-1 cells and GH3 cells, although at a much lower level. There was
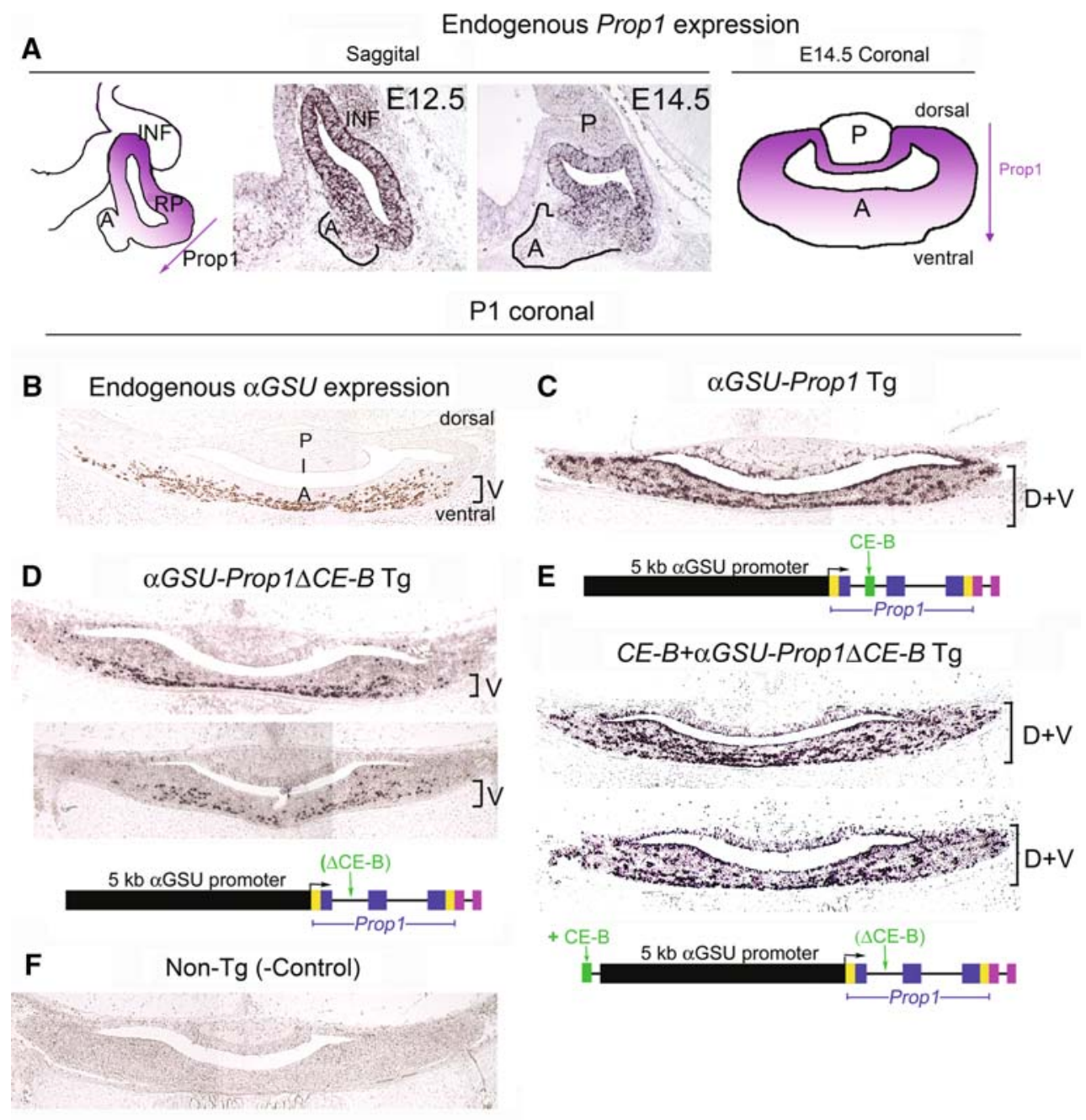

Fig. 5 Transgenic mice reveal functional properties of $C E-B$. A Endogenous Prop1 expression illustrated diagrammatically and with Propl in situ hybridization in sagittal e12.5 and e14.5 mouse and coronal e14.5 pituitaries. A dorsal-to-ventral expression gradient is apparent. The anterior lobe is marked by a black line. B Immunohistochemical staining with $\alpha$ GSU antibody (brown DAB chromagen) reveals normal $\alpha G s u$ expression in the caudomedial and ventral regions of a P1 coronal pituitary expression via IHC. C In situ hybridization for Propl transcripts [purple AP chromagen] reveals that the $\alpha$ Gsu-Propl transgenic construct expression is expanded dorsally in P1 coronal pituitary sections relative to endogenous $\alpha G s u$ expression. D Propl in situ hybridization shows that the $\alpha G s u$ Prop $1 \triangle C E-B$ transgenic construct expression (purple AP chromagen)

was restored to the caudomedial and ventral regions in P1 coronal pituitaries. E Prop1 in situ hybridization shows that the $C E-B+\alpha G s u$ Prop $1 \triangle C E-B$ transgenic expression (purple AP chromagen) was expanded to the dorsal aspects of the pituitary at P1. C-E Representations of the transgenic constructs are shown beneath the appropriate studies. Brackets mark the region for each pituitary in which the transgene expression was detected. F In situ hybridization for Propl in a nontransgenic pituitary gives no signal. DAB, 3,3' diaminobenzidine; AP, alkaline phosphatase; A, anterior lobe; $\mathrm{P}$, posterior lobe; I, intermediate lobe; RP, Rathke's pouch; INF, infindibulum; $v$, ventral expression pattern; $d+v$, dorsal and ventral expression pattern 
no enhancer activity in either the AtT-20 line or the $\alpha \mathrm{T} 3-1$ line. The $C E-C$ putative regulatory element had low enhancer activity in only the CV-1 and AtT-20 cell lines. There are many possible explanations for the weak activity of $C E-B$ and $C E-C$ in cell culture, but the cell culture assays did detect enhancer function. The pituitary-derived cell lines were developed in the different hormone-producing cell lineages, e.g., the $\alpha \mathrm{T} 3-1$ cells are gonadotropelike, whereas GH3 cells are somatotrope-like. Therefore, the differential enhancer activities of the different constructs in these cell lines may be examples of contextspecific activity. In addition, the cell lines may be more representative of differentiated cell types and, because Propl is expressed significantly only during early pituitary development in the rodent (Sornson et al., 1996), these cells may not contain the transcription factors and cofactors necessary for the full activity of the putative enhancers. These enhancers also are orientation-specific. However, other examples of orientation-dependent enhancers have been reported (Cheng et al. 2004; Falvo et al. 2000; Nishimura et al. 2000; Surinya et al. 1998; Swamynathan and Piatigorsky 2002; Wei and Brennan 2000).

Our transgenic experiments shed some light on the function of the $C E-B$ region. In the context of the $\alpha G s u$ promoter, the $C E-B$ element results in dorsal expansion of transgene expression. Although this construct used a heterologous promoter, which allows for the expression of the transgene after the endogenous Propl expression is extinguished, these results provide evidence that the $C E-B$ region in intron 1 of Propl is important for spatial expression. The $C E-B$ region in conjunction with the $\alpha G s u$ promoter will be useful for driving the expression of transgenes in the more dorsal aspects of the developing pituitary. Other studies have shown that the Rbp-J $\kappa$ DNA binding protein, which is the primary mediator of Notch signaling, can directly bind to intron 1 of Propl and is important for the maintenance of Propl expression (Zhu et al. 2006). Taken together, these data suggest an in vivo role for the $C E-B$ in the regulation of Propl expression.

Two kilobase pairs of the Propl promoter proximal region $(C E-A)$ is inadequate for reporter gene expression in transgenic mice, even in the context of $C E-B$. This indicates that additional sequences are necessary for Propl expression in mice. The BAC rescue of Propl $^{-/ \mathrm{df}}$ mice demonstrates that all of the elements necessary for transcriptional regulation of Propl are contained within the BAC. We predict that the remaining critical sequences for Propl expression are within the region immediately surrounding Propl, within $15 \mathrm{~kb}$ upstream and approximately $26 \mathrm{~kb}$ downstream, because there is a disruption in gene order between human and mouse or pig. These critical control sequences are not readily identifiable by genomic sequence comparisons.
In summary, we identified a region, contained within intron 1 of Propl, which is necessary and sufficient for the spatial expression of Propl in the context of a heterologous pituitary specific promoter. While additional regulatory elements remain to be identified by other approaches, the intronic element is worth screening for mutations in unexplained cases of MPHD patients, especially those that appear heterozygous for mutations in PROPI.

Acknowledgments This work was funded by the NIH (T32 GM07863 and T32 GM07315 to RDW, NRSA F32 DK60306 to LTR, R37HD30428 and R01HD34283 to SAC), the Howard Hughes Medical Institute, and the University of Michigan Bioinformatics Program. The authors thank the University of Michigan Transgenic Animal Model Core and their supporting entities: NIH grants (CA46592, AR20557, DK07367), the University of Michigan Center for Organogenesis, the Michigan Economic Development Corporation, and the Michigan Technology Tri-Corridor (Michigan Animal Models Consortium grant 085P1000815). They thank Igor Nasonkin, Frank Probst, and Hoonkyo Suh for their help in performing the initial ClustalW alignments and consensus binding site screenings; Deborah Gumucio and Morris Goodman for kindly providing the primate genomic DNAs; Pam Mellon for providing the $\alpha \mathrm{T} 3-1$ cell lines; Jorge Iniquez for the generous gift of the pDODLO $02 \mathrm{ADH}$ luciferase reporter construct; and Audrey Seasholtz and Sam Holmstrom for their helpful advice.

\section{References}

Agarwal G, Bhatia V, Cook S, Thomas PQ (2000) Adrenocorticotropin deficiency in combined pituitary hormone deficiency patients homozygous for a novel PROP1 deletion. J Clin Endocrinol Metab 85:4556-4561

Ahituv N, Rubin EM, Nobrega MA (2004) Exploiting human-fish genome comparisons for deciphering gene regulation. Hum Mol Genet 13 Spec No 2:R261-R266

Aparicio S, Morrison A, Gould A, Gilthorpe J, Chaudhuri C, et al. (1995) Detecting conserved regulatory elements with the model genome of the Japanese puffer fish, Fugu rubripes. Proc Natl Acad Sci U S A 92:1684-1688

Bagheri-Fam S, Ferraz C, Demaille J, Scherer G, Pfeifer D (2001) Comparative genomics of the SOX9 region in human and Fugu rubripes: conservation of short regulatory sequence elements within large intergenic regions. Genomics 78:73-82

Bhangoo AP, Hunter CS, Savage JJ, Anhalt H, Pavlakis S, et al. (2006) Clinical case seminar: a novel LHX3 mutation presenting as combined pituitary hormonal deficiency. J Clin Endocrinol Metab 91:747-753

Boffelli D, McAuliffe J, Ovcharenko D, Lewis KD, Ovcharenko I, et al. (2003) Phylogenetic shadowing of primate sequences to find functional regions of the human genome. Science 299:13911394

Boffelli D, Nobrega MA, Rubin EM (2004) Comparative genomics at the vertebrate extremes. Nat Rev Genet 5:456-465

Bottner A, Keller E, Kratzsch J, Stobbe H, Weigel JF, et al. (2004) PROP1 mutations cause progressive deterioration of anterior pituitary function including adrenal insufficiency: a longitudinal analysis. J Clin Endocrinol Metab 89:5256-5265

Braga S, Phillips JA 3rd, Joss E, Schwarz H, Zuppinger K (1986) Familial growth hormone deficiency resulting from a $7.6 \mathrm{~kb}$ deletion within the growth hormone gene cluster. Am J Med Genet 25:443-452 
Bray N, Dubchak I, Pachter L (2003) AVID: A global alignment program. Genome Res 13:97-102

Brinkmeier ML, Potok MA, Cha KB, Gridley T, Stifani S, et al. (2003) TCF and Groucho-related genes influence pituitary growth and development. Mol Endocrinol 17:2152-2161

Buckwalter MS, Katz RW, Camper SA (1991) Localization of the panhypopituitary dwarf mutation (df) on mouse chromosome 11 in an intersubspecific backcross. Genomics 10:515-526

Carninci P, Waki K, Shiraki T, Konno H, Shibata K, et al. (2003) Targeting a complex transcriptome: the construction of the mouse full-length cDNA encyclopedia. Genome Res 13:12731289

Charles MA, Suh H, Hjalt TA, Drouin J, Camper SA, et al. (2005) PITX genes are required for cell survival and Lhx3 activation. Mol Endocrinol 19:1893-1903

Cheng HC, Wang CK, Upholt WB (2004) Transcriptional regulation of Msx2 in the AERs of developing limbs is dependent on multiple closely spaced regulatory elements. Dev Biol 270:513524

Cogan J, Wu W, Phillips JI, Arnhold I, Agapito A, et al. (1998) The PROP1 2-base pair deletion is a common cause of combined pituitary hormone deficiency. J Clin Endocrinol Metab 83:33463349

Cohen LE, Wondisford FE, Radovick S (1996) Role of Pit-1 in the gene expression of growth hormone, prolactin, and thyrotropin. Endocrinol Metab Clin North Am 25:523-540

Couronne O, Poliakov A, Bray N, Ishkhanov T, Ryaboy D, et al. (2003) Strategies and tools for whole-genome alignments. Genome Res 13:7

Cushman LJ, Camper SA (2001) Molecular basis of pituitary dysfunction in mouse and human. Mamm Genome 12:485-494

Cushman LJ, Watkins-Chow DE, Brinkmeier ML, Raetzman LT, Radak AL, et al. (2001) Persistent Propl expression delays gonadotrope differentiation and enhances pituitary tumor susceptibility. Hum Mol Genet 10:1141-1153

Dasen JS, Barbera JP, Herman TS, Connell SO, Olson L, et al. (2001) Temporal regulation of a paired-like homeodomain repressor/ TLE corepressor complex and a related activator is required for pituitary organogenesis. Genes Dev 15:3193-3207

Deladoey J, Fluck C, Buyukgebiz A, Kuhlmann BV, Eble A, et al. (1999) "Hot spot"' in the PROP1 gene responsible for combined pituitary hormone deficiency. J Clin Endocrinol Metab 84:16451650

Duquesnoy P, Roy A, Dastot F, Ghali I, Teinturier C, et al. (1998) Human Prop-1: cloning, mapping, genomic structure. Mutations in familial combined pituitary hormone deficiency. FEBS Lett 437:216-220

Ewing B, Green P (1998) Base-calling of automated sequencer traces using phred. II. Error probabilities. Genome Res 8:186-194

Falvo JV, Parekh BS, Lin CH, Fraenkel E, Maniatis T (2000) Assembly of a functional beta interferon enhanceosome is dependent on ATF-2-c-jun heterodimer orientation. Mol Cell Biol 20:4814-4825

Fluck C, Deladoey J, Rutishauser K, Eble A, Marti U, et al. (1998) Phenotypic variability in familial combined pituitary hormone deficiency caused by a PROP1 gene mutation resulting in the substitution of $\mathrm{Arg} \rightarrow$ Cys at codon 120 (R120C). J Clin Endocrinol Metab 83:3727-3734

Gage PJ, Brinkmeier ML, Scarlett LM, Knapp LT, Camper SA, et al. (1996a) The Ames dwarf gene, $d f$, is required early in pituitary ontogeny for the extinction of Rpx transcription and initiation of lineage specific cell proliferation. Mol Endocrinol 10:1570-1581

Gage PJ, Roller ML, Saunders TL, Scarlett LM, Camper SA (1996b) Anterior pituitary cells defective in the cell-autonomous factor, $d f$, undergo cell lineage specification but not expansion. Development 122:151-160
Gordon D, Abajian C, Green P (1998) Consed: a graphical tool for sequence finishing. Genome Res 8:195-202

Guy JC, Hunter CS, Showalter AD, Smith TP, Charoonpatrapong K, et al. (2004) Conserved amino acid sequences confer nuclear localization upon the Prophet of Pit-1 pituitary transcription factor protein. Gene 336:263-273

Iniguez-Lluhi JA, Lou DY, Yamamoto KR (1997) Three amino acid substitutions selectively disrupt the activation but not the repression function of the glucocorticoid receptor $\mathrm{N}$ terminus. J Biol Chem 272:4149-4156

Japon MA, Rubinstein M, Low MJ (1994) In situ hybridization analysis of anterior pituitary hormone gene expression during fetal mouse development. J Histochem Cytochem 42:1117-1125

Kendall SK, Gordon DF, Birkmeier TS, Petrey D, Sarapura VD, et al. (1994) Enhancer-mediated high level expression of mouse pituitary glycoprotein hormone alpha-subunit transgene in thyrotropes, gonadotropes, and developing pituitary gland. Mol Endocrinol 8:1420-1433

Kent WJ (2002) BLAT-the BLAST-like alignment tool. Genome Res 12:656-664

Kent WJ, Sugnet CW, Furey TS, Roskin KM, Pringle TH, et al. (2002) The human genome browser at UCSC. Genome Res 12:996-1006

Kleinjan DA, van Heyningen V (2005) Long-range control of gene expression: emerging mechanisms and disruption in disease. Am J Hum Genet 76:8-32

Komminoth P (1996) Detection of mRNA in tissue sections using DIG-labeled RNA and oligonucleotide probes. In: Nonradioactive In Situ hybridization application manual, 2nd edn. Mannheim, Boehringer Mannheim, Germany, pp 126-135

Lang D, Brown CB, Milewski R, Jiang YQ, Lu MM, et al. (2003) Distinct enhancers regulate neural expression of Pax7. Genomics 82:553-560

Laumonnier F, Ronce N, Hamel BC, Thomas P, Lespinasse J, et al. (2002) Transcription factor SOX3 is involved in X-linked mental retardation with growth hormone deficiency. Am J Hum Genet 71:1450-1455

Lettice LA, Heaney SJ, Purdie LA, Li L, de Beer P, et al. (2003) A long-range Shh enhancer regulates expression in the developing limb and fin and is associated with preaxial polydactyly. Hum Mol Genet 12:1725-1735

Machinis K, Pantel J, Netchine I, Leger J, Camand OJ, et al. (2001) Syndromic short stature in patients with a germline mutation in the LIM homeobox LHX4. Am J Hum Genet 69:961-968

Matsumoto A, Ishii S (eds) (1987) Atlas of Endocrine Organs (Tokyo: Springer-Verlag)

Mendonca B, Osorio M, Latronico A, Estefan V, Lo L, et al. (1999). Longitudinal hormonal and pituitary imaging changes in two females with combined pituitary hormone deficiency due to deletion of A301,G302 in the PROP1 gene. J Clin Endocrinol Metab 84:942-945

Mullis P, Patel M, Brickell PM, Brook CG (1990) Isolated growth hormone deficiency: analysis of the growth hormone (GH)releasing hormone gene and the $\mathrm{GH}$ gene cluster. J Clin Endocrinol Metab 70:187-191

Nakamura S, Ohtsuru A, Takamura N, Kitange G, Tokunaga Y, et al. (1999a) Prop-1 gene expression in human pituitary tumors. J Clin Endocrinol Metab 84:2581-2584

Nakamura Y, Usui T, Mizuta H, Murabe H, Muro S, et al. (1999b) Characterization of Prophet of Pit-1 gene expression in normal pituitary and pituitary adenomas in humans. J Clin Endocrinol Metab 84:1414-1419

Nasonkin IO, Ward RD, Raetzman LT, Seasholtz AF, Saunders TL, et al. (2004) Pituitary hypoplasia and respiratory distress syndrome in Prop1 knockout mice. Hum Mol Genet 13:27272735 
Nei M, Xu P, Glazko G (2001) Estimation of divergence times from multiprotein sequences for a few mammalian species and several distantly related organisms. Proc Natl Acad Sci U S A 98:24972502

Netchine I, Sobrier ML, Krude H, Schnabel D, Maghnie M, et al. (2000) Mutations in LHX3 result in a new syndrome revealed by combined pituitary hormone deficiency. Nat Genet 25:182-186

Nishimura S, Takahashi S, Kuroha T, Suwabe N, Nagasawa T, et al. (2000) A GATA box in the GATA-1 gene hematopoietic enhancer is a critical element in the network of GATA factors and sites that regulate this gene. Mol Cell Biol 20:713-723

Nobrega MA, Pennacchio LA (2004) Comparative genomic analysis as a tool for biological discovery. J Physiol 554:31-39

Nobrega MA, Ovcharenko I, Afzal V, Rubin EM (2003) Scanning human gene deserts for long-range enhancers. Science 302:413

Parks JS, Brown MR, Hurley DL, Phelps CJ, Wajnrajch MP (1999) Heritable disorders of pituitary development. J Clin Endocrinol Metab 84:4362-4370

Pennacchio LA, Rubin EM (2001) Genomic strategies to identify mammalian regulatory sequences. Nat Rev Genet 2:100-109

Peschon JJ, Behringer RR, Brinster RL, Palmiter RD (1987) Spermatid-specific expression of protamine 1 in transgenic mice. Proc Natl Acad Sci U S A 84:5316-5319

Pfäffle RW, DiMattia GE, Parks JS, Brown MR, Wit JM, et al. (1992) Mutation of the POU-specific domain of Pit-1 and hypopituitarism without pituitary hypoplasia. Science 257:1118-1121

Plessy C, Dickmeis T, Chalmel F, Strahle U (2005) Enhancer sequence conservation between vertebrates is favoured in developmental regulator genes. Trends Genet 21:207-210

Procter AM, Phillips JA 3rd, Cooper DN (1998) The molecular genetics of growth hormone deficiency. Hum Genet 103:255-272

Radovick S, Nations M, Du Y, Berg LA, Weintraub BD, et al. (1992) A mutation in the POU-Homeodomain of Pit-1 responsible for combined pituitary hormone deficiency. Science 257:1115-1117

Raetzman LT, Ward R, Camper SA (2002) Lhx4 and Prop1 are required for cell survival and expansion of the pituitary primordia. Development 129:4229-4239

Raetzman LT, Ross SA, Cook S, Dunwoodie SL, Camper SA, et al. (2004) Developmental regulation of Notch signaling genes in the embryonic pituitary: Prop1 deficiency affects Notch2 expression. Dev Biol 265:329-340

Reynaud R, Barlier A, Vallette-Kasic S, Saveanu A, Guillet MP, et al. (2005) An uncommon phenotype with familial central hypogonadism caused by a novel PROP1 gene mutant truncated in the transactivation domain. J Clin Endocrinol Metab 90:4880-4887

Showalter AD, Smith TP, Bennett GL, Sloop KW, Whitsett JA, et al. (2002) Differential conservation of transcriptional domains of mammalian Prophet of Pit-1 proteins revealed by structural studies of the bovine gene and comparative functional analysis of the protein. Gene 291:211-221

Skelly RH, Korbonits M, Grossman A, Besser GM, Monson JP, et al. (2000) Expression of the pituitary transcription factor Ptx-1, but not that of the trans-activating factor prop-1, is reduced in human corticotroph adenomas and is associated with decreased alphasubunit secretion. J Clin Endocrinol Metab 85:2537-2542

Sloop KW, McCutchan Schiller A, Smith TP, Blanton JR Jr, Rohrer GA, et al. (2000) Biochemical and genetic characterization of the porcine Prophet of Pit-1 pituitary transcription factor. Mol Cell Endocrinol 168:77-87

Sornson MW, Wu W, Dasen JS, Flynn SE, Norman DJ, et al. (1996) Pituitary lineage determination by the Prophet of Pit-1 homeodomain factor defective in Ames dwarfism. Nature 384:327-333

Suh H, Gage PJ, Drouin J, Camper SA (2002) Pitx2 is required at multiple stages of pituitary organogenesis: pituitary primordium formation and cell specification. Development 129:329-337

Surinya KH, Cox TC, May BK (1998) Identification and characterization of a conserved erythroid-specific enhancer located in intron 8 of the human 5 -aminolevulinate synthase 2 gene. J Biol Chem 273:16798-16809

Swamynathan SK, Piatigorsky J (2002) Orientation-dependent influence of an intergenic enhancer on the promoter activity of the divergently transcribed mouse Shsp/alpha B-crystallin and Mkbp/HspB2 genes. J Biol Chem 277:49700-49706

Szeto DP, Rodriguez-Estaban C, Ryan AK, O'Connell SM, Liu F, et al. (1999) Role of Bicoid-related homeodomain factor Pitx 1 in specifying hindlimb morphogenesis and pituitary development. Genes Dev 13:484-494

Tajima T, Hattorri T, Nakajima T, Okuhara K, Sato K, et al. (2003) Sporadic heterozygous frameshift mutation of HESX1 causing pituitary and optic nerve hypoplasia and combined pituitary hormone deficiency in a Japanese patient. J Clin Endocrinol Metab 88:45-50

Tatsumi K, Miyai K, Notomi T, Kaibe K, Amino N, et al. (1992) Cretinism with combined hormone deficiency caused by a mutation in the PIT1 gene. Nat Genet 1:56-58

Usui T, Nakamura Y, Mizuta H, Murabe H, Muro S, et al. (2000) Functional significance of prop-1 gene expression in pituitary adenomas. Endocr J 47 Suppl:S85-S89

Vesper AH, Raetzman LT, Camper SA (2006) Role of prophet of Pit1 (PROP1) in gonadotrope differentiation and puberty. Endocrinology 147:1654-1663

Vimpani GV, Vimpani AF, Lidgard GP, Cameron EHD, Farquhar JW (1977) Prevalence of severe growth hormone deficiency. Br Med J 2:427-430

Ward RD, Raetzman LT, Suh H, Stone BM, Nasonkin IO, et al. (2005) Role of PROP1 in pituitary gland growth. Mol Endocrinol 19:698-710

Wei W, Brennan MD (2000) Polarity of transcriptional enhancement revealed by an insulator element. Proc Natl Acad Sci U S A 97:14518-14523

Williams SH, Mouchel N, Harris A (2003) A comparative genomic analysis of the cow, pig, and human CFTR genes identifies potential intronic regulatory elements. Genomics 81:628-639

Wu W, Cogan JD, Pfaffle RW, Dasen JS, Frisch H, et al. (1998) Mutations in PROP1 cause familial combined pituitary hormone deficiency. Nat Genet 18:147-149

Zerucha T, Stuhmer T, Hatch G, Park BK, Long Q, et al. (2000) A highly conserved enhancer in the Dlx5/Dlx6 intergenic region is the site of cross-regulatory interactions between $D l x$ genes in the embryonic forebrain. J Neurosci 20:709-721

Zhu X, Zhang J, Tollkuhn J, Ohsawa R, Bresnick EH, et al. (2006) Sustained Notch signaling in progenitors is required for sequential emergence of distinct cell lineages during organogenesis. Genes Dev 20:2739-2753 